\title{
Article \\ Nonuniform Deformation of Cell Structures Owing to Plastic Stress Wave Propagation
}

\author{
Kohei Tateyama ${ }^{1, *}$ and Hiroyuki Yamada ${ }^{2}$ \\ 1 Department of Mechanical Engineering, Ritsumeikan University, 1-1-1 Nojihigashi, Kusatsu 525-8577, Japan \\ 2 Department of Mechanical Engineering, National Defense Academy, 1-10-20, Hashirimizu, \\ Yokosuka 239-8686, Japan; ymda@nda.ac.jp \\ * Correspondence: koheit@fc.ritsumei.ac.jp; Tel.: +81-77-561-2835
}

check for updates

Citation: Tateyama, K.; Yamada, H. Nonuniform Deformation of Cell Structures Owing to Plastic Stress Wave Propagation. Appl. Mech. 2021, 2, 911-931. https://doi.org/10.3390/ applmech2040053

Received: 16 September 2021 Accepted: 3 November 2021 Published: 5 November 2021

Publisher's Note: MDPI stays neutral with regard to jurisdictional claims in published maps and institutional affiliations.

Copyright: (C) 2021 by the authors. Licensee MDPI, Basel, Switzerland. This article is an open access article distributed under the terms and conditions of the Creative Commons Attribution (CC BY) license (https:// creativecommons.org/licenses/by/ $4.0 /)$.

\begin{abstract}
In cell structures, unlike in dense bodies, nonuniform deformation occurs from the impact end, even at velocities in the order of tens to hundreds of meters per second. In this study, we experimentally examine the nonuniform deformation mechanism of cell structures. They prepared two kinds of specimens: nickel foam (Ni foam) and silicone-rubber-filled nickel foam (Ni/silicone foam). As a dynamic and impact test method (compression velocity of $20 \mathrm{~m} / \mathrm{s}$ or more), we used a dynamic and impact load-measuring apparatus with opposite load cells to evaluate the loads on both ends of the specimen in one test. At compression velocities of $20 \mathrm{~m} / \mathrm{s}$ or less, no nonuniform deformations were observed in the $\mathrm{Ni}$ foam and the $\mathrm{Ni}$ / silicone foam, and the loads on the impact and the fixed ends achieved force equilibrium. The Ni foam showed no change with an increasing strain rate, and the $\mathrm{Ni}$ /silicone foam showed a strong strain rate dependence of the flow stress. At a compression velocity of approximately $26 \mathrm{~m} / \mathrm{s}$, the loads differed at the two ends of the $\mathrm{Ni}$ /silicone foam, and we observed nonuniform deformation from the impact end. The results of the visualization of the load and deformation behavior obtained from both ends of the specimen revealed that the velocity of the plastic stress wave and the length of the specimens are important for nonuniform deformation.
\end{abstract}

Keywords: cell structures; stress wave; impact deformation; nonuniform deformation

\section{Introduction}

Such cell structures as foam or honeycomb formations are widely used in shockabsorbing materials owing to their low weight and excellent shock-absorbing capacities. Unlike dense bodies, cell structures undergo plateau deformation, whereby a strain increase is not accompanied by a stress increase [1,2]. Plateau deformation occurs from the collapse of cells (voids). However, the mechanical properties of cell structures change with geometrical conditions, including the shape, size, and number of cells. Therefore, many studies have investigated the mechanical properties of various cell structures. For example, a constitutive law for a material was formulated by treating cell structure as a material $[1,2]$. The effect of the cell structure's shape on its mechanical properties has also been reported [3-6] and the effect of the substance (typically air) that fills the cells [7,8]. Studies have conducted impact tests, such as the split Hopkinson pressure bar (SHB) method, to investigate the strain rate dependence $[9,10]$. However, these tests are only valid if the material is deformed uniformly, and different tests are required if nonuniform deformation, which means the deformation from the impact end, occurs due to the inertia effect.

Studies have described that when a hyper-velocity impact load in the order of several kilometers per second is applied to a dense solid body, a discontinuity surface is generated inside it and propagates as a wave (shock wave), producing a nonuniform deformation in the body [11,12]. This shock wave was generated in a solid. However, unlike in dense bodies, in cell structures, nonuniform deformation occurs from the impact end, even at velocities in the order of tens to hundreds of meters per second. For example, 
Elnasri et al. [13] and Pattofatto et al. [14] used the direct-impact Hopkinson pressure bar (DHB) method to evaluate large deformations in a cell structure and clarified that a foamed aluminum (Al) alloy shows nonuniform deformation. They presented a method for acquiring the wavefront of a nonuniform deformation by visually expressing the deformation behavior with digital image correlation. Wang et al. [15] also used DHB and digital image correlation to demonstrate that when an impact load is applied to a foamed $\mathrm{Al}$ alloy, nonuniform deformation occurs sequentially from the impact end, and the loads on the impact and fixed ends might not achieve force equilibrium. Gaitanaros and Kyriakides [16] built a numerical analysis model by correlation between the propagation speed of the leading edge of the nonuniform deformation generated from the impact end and the deformation rate. Their experiment analytically showed that when a nonuniform deformation occurs from the impact end in a foamed Al alloy, the Rankine-Hugoniot relation [12], which is used for discussing shock waves in solid bodies, is satisfied at the boundary between the nonuniformly deformed and undeformed areas. Although these studies reported the transition velocity, which is the boundary velocity between the uniform and nonuniform deformations, a more detailed explanation of the nonuniform deformation mechanism is necessary. Under conditions where force equilibrium is not achieved, most studies using the DHB method require the following two tests to obtain the load history at both the impact and fixed ends: (1) attaching the specimen to a projectile and launching it, and (2) attaching the specimen to a transmitted bar and fixing it. However, since these tests must be performed twice with different specimens, the load at both ends of the specimen cannot be measured in a one-time test.

In this study, we overcame the drawbacks of the DHB method using a test apparatus that can evaluate the load state at the impact and fixed ends in a one-time test. We focused on the stress waves propagating in the specimen and clarified the nonuniform deformation mechanism of the cell structure from our obtained test results.

\section{Specimen}

\subsection{Nickel Foam}

In this study, we used nickel foam with an open cell (Sumitomo Electric Industries, Figure 1 ) as a specimen for observing the nonuniform deformation of the cell structure. The specimens were cut into rectangular parallelepipeds with a $20 \mathrm{~mm}$ long, $10 \mathrm{~mm} \times 10 \mathrm{~mm}$ cross-section using a wire discharge. Figure 2 shows a 3D image of the cell shape of a typical Ni foam observed by an X-ray computed tomography system. Table 1 lists the cell shape parameters observed by X-ray CT. The cells are composed of dense solid columns (pillars), nodes, and pores. They have an open cell structure and are connected in three dimensions. In addition, the Ni foam has an irregular cell structure with nonuniform cell shapes. Bulk density $\rho_{\text {cell }}$ of the $\mathrm{Ni}$ foam was approximately $450 \mathrm{~kg} / \mathrm{m}^{3}$.

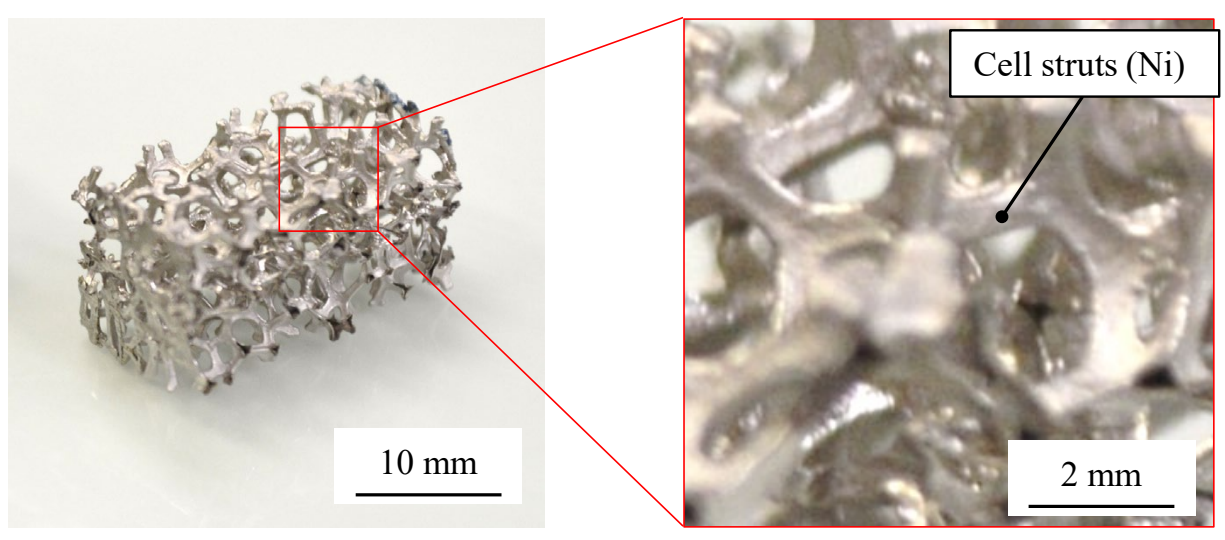

Figure 1. External view of foamed Ni. 


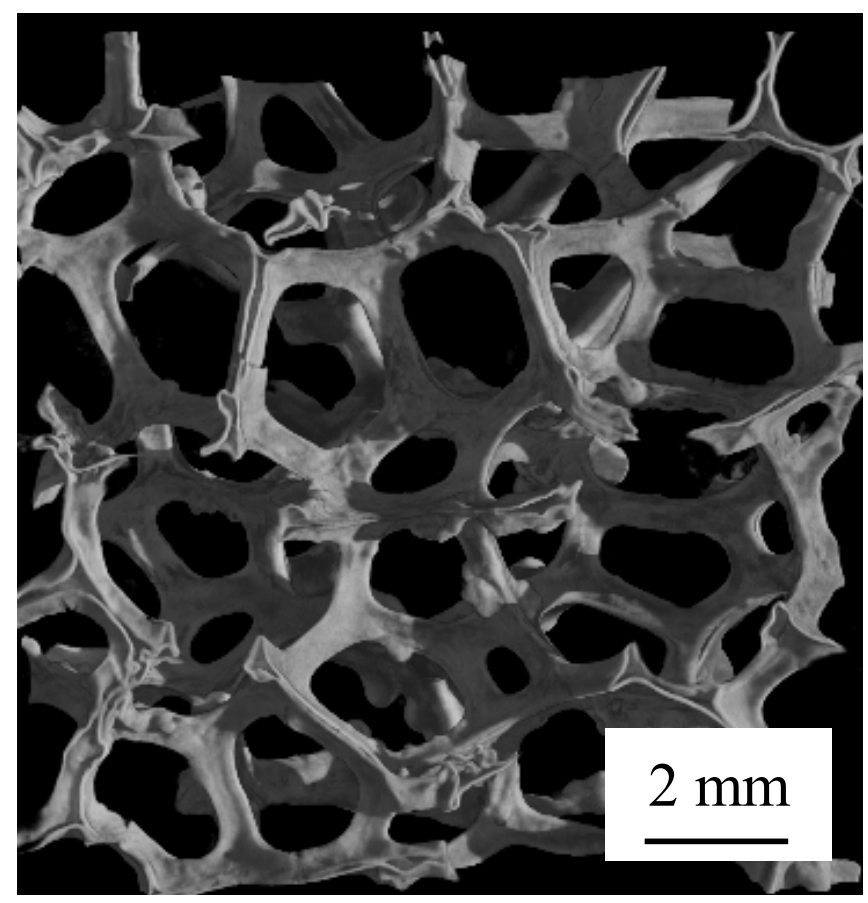

Figure 2. 3D image of typical Ni foam.

Table 1. Cell shape parameters of $\mathrm{Ni}$ foam and $\mathrm{Ni} /$ silicone foam.

\begin{tabular}{|c|c|c|}
\hline Specimen & Ni Foam & Ni/Silicone Foam \\
\hline Expansion ratio & \multicolumn{2}{|c|}{ Average value: 18.7 (Standard deviation: 1.91) } \\
\hline Porosity & \multicolumn{2}{|c|}{ Average value: $95 \%$ (Standard deviation: 0.16 ) } \\
\hline Dimensions & \multicolumn{2}{|c|}{$20 \times 10 \times 10 \mathrm{~mm}^{3}$} \\
\hline Bulk density & $450 \mathrm{~kg} / \mathrm{m}^{3}$ & $1300 \mathrm{~kg} / \mathrm{m}^{3}$ \\
\hline Filling in the pores & Air & Silicone rubber \\
\hline Cell size & \multicolumn{2}{|c|}{$3.2 \mathrm{~mm}$} \\
\hline Aperture length & \multicolumn{2}{|c|}{$1.2 \mathrm{~mm}$} \\
\hline Cell struts thickness & \multicolumn{2}{|c|}{$0.05 \mathrm{~mm}$} \\
\hline Cell shape & \multicolumn{2}{|c|}{ Dodecahedron } \\
\hline Anisotropy & \multicolumn{2}{|c|}{ Isotropic } \\
\hline
\end{tabular}

\subsection{Silicone Rubber-Filled Nickel Foam}

We changed the compressive deformation behavior of the Ni foam and the siliconerubber-filled nickel foam (Ni/silicone foam) by filling the former with silicone rubber and heat-curing it at $423 \mathrm{~K}$ for $2100 \mathrm{~s}$ in a vacuum oven (ESPEC Co. (Osaka, Japan), VAC-301). Figure 3 shows the $\mathrm{Ni}$ /silicone foam. As shown in Table 1, the specimen's shape resembles those described in the previous section, and its density was approximately $1300 \mathrm{~kg} / \mathrm{m}^{3}$. The silicone rubber (Dow Corning (Midland, MI, USA), Sylgard 527) used for the filling consisted of a main agent and a curing agent in a 1:2 ratio. The density of the silicone rubber alone was approximately $1000 \mathrm{~kg} / \mathrm{m}^{3}$. Although Ni/silicone foam has the same cell structure as $\mathrm{Ni}$ foam, it has a different strain rate dependence because they have different parameters of Young's modulus, density, and stress wave speed. Therefore, we clarified the compressive deformation behavior of the cell structure by performing compression tests on the $\mathrm{Ni}$ foam and the $\mathrm{Ni} /$ silicone foam in a wide strain rate range.

\subsection{Pure Nickel}

To investigate the effect of the base material of $\mathrm{Ni}$ foam, a dense body of pure nickel $(99.7 \%)$ were prepared as a specimen. The $4 \mathrm{~mm}$-diameter cylindrical specimen was $6 \mathrm{~mm}$ high. 


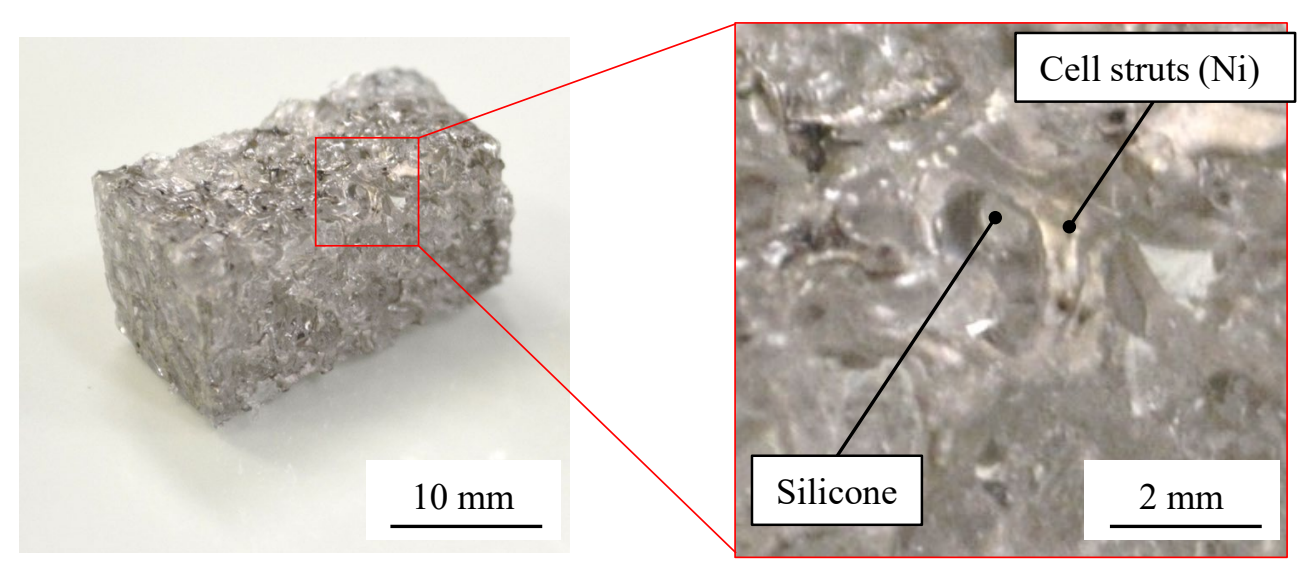

Figure 3. External and enlarged view of $\mathrm{Ni}$ /silicone foam.

\subsection{Silicone Rubber}

To investigate the mechanical properties of silicone rubber, we prepared a specimen made of silicone rubber used in 2.2, which is the filling material for Ni/silicone foam. The dimensions of the specimen were $10 \mathrm{~mm} \times 10 \mathrm{~mm}$ (cross section) and $10 \mathrm{~mm}$ (height). The dimensions and density of the $\mathrm{Ni}$ and the silicone rubber are summarized in Table 2.

Table 2. The dimensions and density of the Ni and silicone rubber.

\begin{tabular}{ccc}
\hline Specimen & Dimensions & Density \\
\hline Pure Ni & $\phi 4 \times 6 \mathrm{~mm}^{3}$ & $8900 \mathrm{~kg} / \mathrm{m}^{3}$ \\
Silicone rubber & $10 \times 10 \times 10 \mathrm{~mm}^{3}$ & $1000 \mathrm{~kg} / \mathrm{m}^{3}$ \\
\hline
\end{tabular}

\section{Compression Test}

\subsection{Quasi-Static Test}

A quasi-static test was performed using a universal testing machine (INSTRON (Norwood, MA, USA), 5500R) at room temperature. The compression velocities were $3.4 \times 10^{-3}, 3.4 \times 10^{-2}$, and $3.4 \times 10^{-1} \mathrm{~s}^{-1}$ (strain rates: $1.7 \times 10^{-4}, 1.7 \times 10^{-3}$, and $\left.1.7 \times 10^{-2} \mathrm{~s}^{-1}\right)$. The test was performed three times at each velocity.

\subsection{Dynamic/Impact Test}

\subsubsection{SHB Method}

The SHB method $[17,18]$ is a typical test method in which an elastic stress bar is used as an impact load sensor. We used it for pure Ni. This method is widely recognized as a rapid deformation test method with high reliability for solid materials. The average strain rates obtained in it were $1.4 \times 10^{2}$ and $8.3 \times 10^{2} \mathrm{~s}^{-1}$.

\subsubsection{Dynamic and Impact Load-Measuring Apparatus with Opposite Load Cells}

Generally, the SHB method is also used to evaluate the impact compression characteristics of dense materials. However, because the cell structure used in this study undergoes large deformation over a long period of time, a sufficient amount of strain cannot be obtained by the SHB method, resulting in a deformation of constant duration, depending on the bar length. In such cases, the DHB method is often used because, compared to the SHB method, it has no incident bar and can be used to measure a large deformation by lengthening the transmitted bar. However, as mentioned above, when the DHB method is used, the loads on the fixed and impact ends must be obtained from different specimens, and the force equilibrium cannot be evaluated using the same specimen. 
To overcome these issues, in a previous study, we developed dynamic and impact loadmeasuring apparatus with opposite load cells that can evaluate the force equilibrium and large deformations of a specimen in a one-time test $[19,20]$. Figure 4 shows their schematics. The test apparatus consists of a load measurement section, a movable mechanism, and a displacement measurement section. For the load measurement section, a universal rate range load cell [21] measured the load over a long period by reducing the disturbance due to the reflection and the interference of stress waves even at a dynamic strain rate. Figure 5 shows a schematic view of the universal rate range load cell (hereafter URR load cell). The URR load cell is composed of a stress detection part and a stress transmission part. The stress waves were measured using a semiconductor strain gauge with a gauge factor of $164 \pm 3 \%$ (Kyowa Electronic Instruments (Tokyo, Japan), KSP-1-350-E4) attached to the center of the stress detection part. In this configuration, a $1 \mathrm{MHz}$ low-pass filter was used to remove electrical noise. The URR load cell has a capacity of $12 \mathrm{kN}$ and a theoretical natural period of $0.013 \mathrm{~ms}$. With URR load cell, the reflected stress waves can be reduced by increasing the cross-sectional area ratio between the measurement and transmission sections. In this apparatus, URR load cells are used for all movable load cells and stationary load cells.

(a)

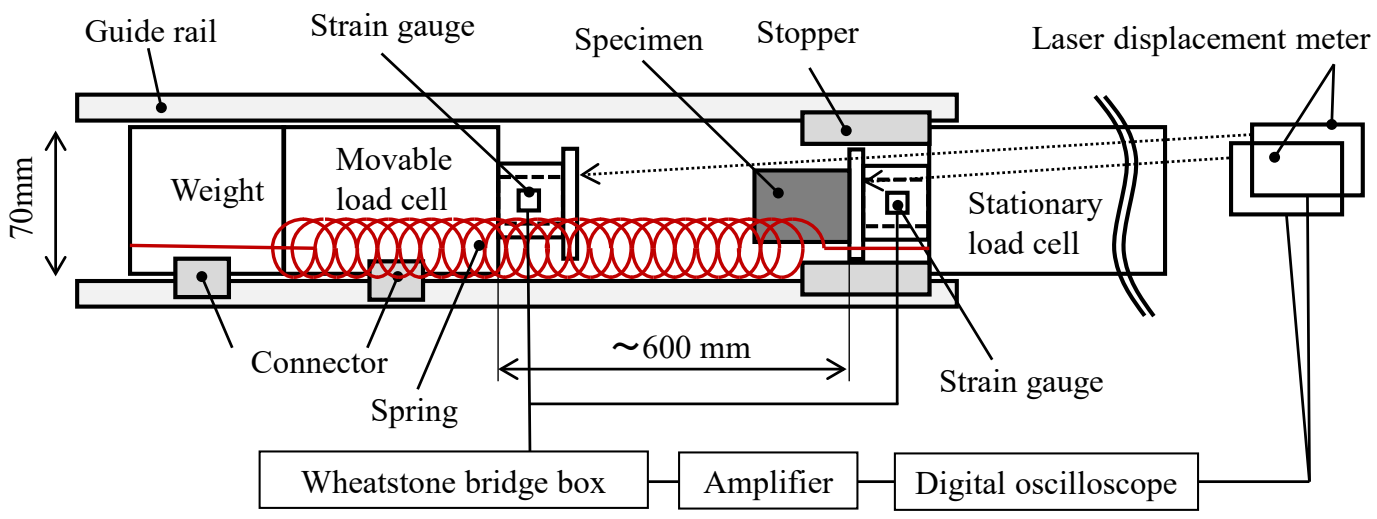

(b)

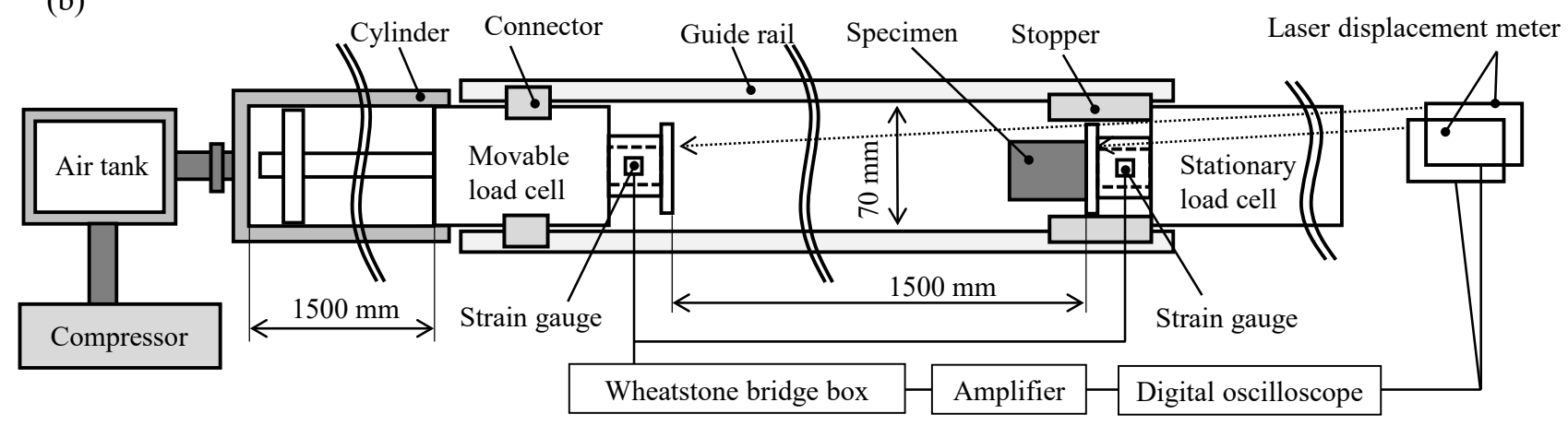

Figure 4. Schematics of dynamic (a) and impact (b) load-measuring apparatus with opposite load cells.

The movable mechanism allows the use of two loading methods, depending on the strain rate. As shown in Figure 4a, the loading method given by a tension spring was used for the dynamic compression test. In addition, for the impact compression test, the injection method with compressed air was used as shown in Figure $4 \mathrm{~b}$. By selecting the movable mechanism, it is possible to test in a wide compression velocities range. Two laser displacement meters (KEYENCE (Osaka, Japan), LK-G5000) with a sampling rate of $200 \mathrm{kHz}$ were used in the displacement measurement section. We measured the displacements of the movable and stationary load cells and calculated the specimen's displacement by their differences. The deformations of the movable and stationary load cells (the stiffness of the test apparatuses) were also measured in advance and subtracted from the test results. 


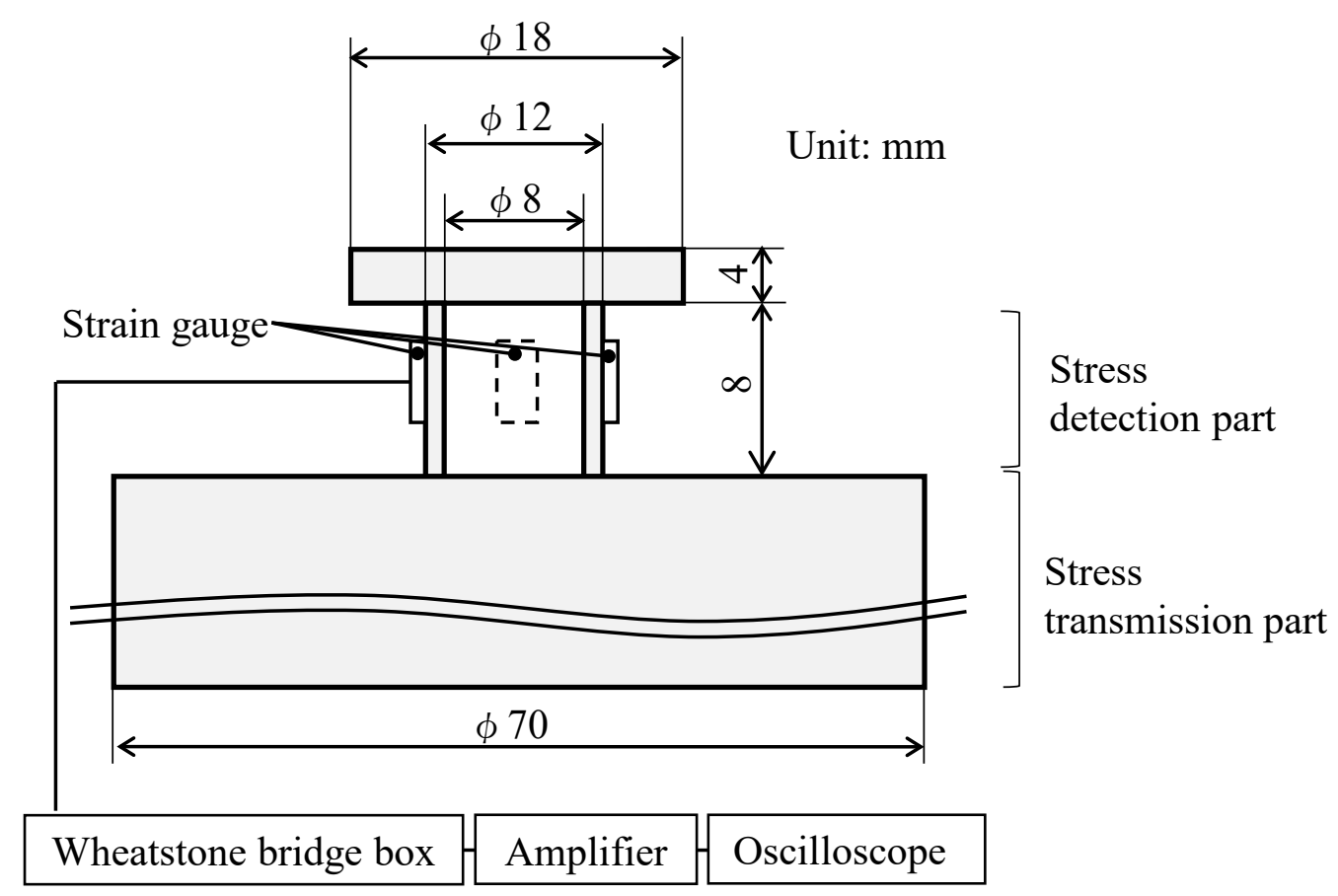

Figure 5. Schematic view of universal rate range load cell.

The compression velocities obtained using this test apparatus was $1.0 \mathrm{~m} / \mathrm{s}$ (strain rate: $4.7 \times 10^{1} \mathrm{~s}^{-1}$ ) in the dynamic test and $7.6 \mathrm{~m} / \mathrm{s}$ (strain rate: $3.8 \times 10^{2} \mathrm{~s}^{-1}$ ) and $26.0 \mathrm{~m} / \mathrm{s}$ (strain rate: $1.3 \times 10^{3} \mathrm{~s}^{-1}$ ) in the impact test. In the dynamic test, we confirmed that the movable load cell can compress the specimen at a constant velocity without deceleration. The deformation behavior of the specimen during the test was captured using a high-speed camera (nac Image Technology (Tokyo, Japan), HX-3) at a frame rate of 100,000 fps, a shutter interval of $3.0 \mu \mathrm{s}$, and an image size of $384 \times 184$ pixels. The field of view is a single plane.

\section{Results of Compression Tests of Constituent Materials}

\subsection{Pure Ni}

The compression characteristics of pure Ni were investigated through quasi-static and impact compression tests (SHB method). Figure 6 shows the obtained true stress-true strain rate relationships. Here, true stress $\sigma$ increases at each true strain, caused by true strain rate $\dot{\varepsilon}$ increase:

$$
\sigma=K \dot{\varepsilon}^{m},
$$

where $K$ is a constant and $m$ is the strain rate sensitivity index, which determines the increase in the true stress with a growing true strain rate and is represented by a slope in the double logarithmic graph. The results indicate $m \leq 0.009$, which is an exceedingly small value. Therefore, the strain rate dependence of the stress between the true strains of 0.05 and 0.2 is small for pure $\mathrm{Ni}$.

\subsection{Silicone Rubber}

As with pure $\mathrm{Ni}$, quasi-static and impact compression tests (with the load-measuring apparatus with opposite load cells) were performed to determine the compression characteristics of the silicone rubber. The obtained true stress-true strain rate relationships are shown in Figure 7. Although there is no change in the true stress with the quasi-static true strain rate, Figure 7 shows that the silicone rubber alone had a higher strain rate sensitivity between $1.7 \times 10^{-2}$ and $8.2 \times 10^{2} \mathrm{~s}^{-1}$ than during the quasi-static test. This finding confirmed that silicone rubber has a strain rate dependence of the stress. 


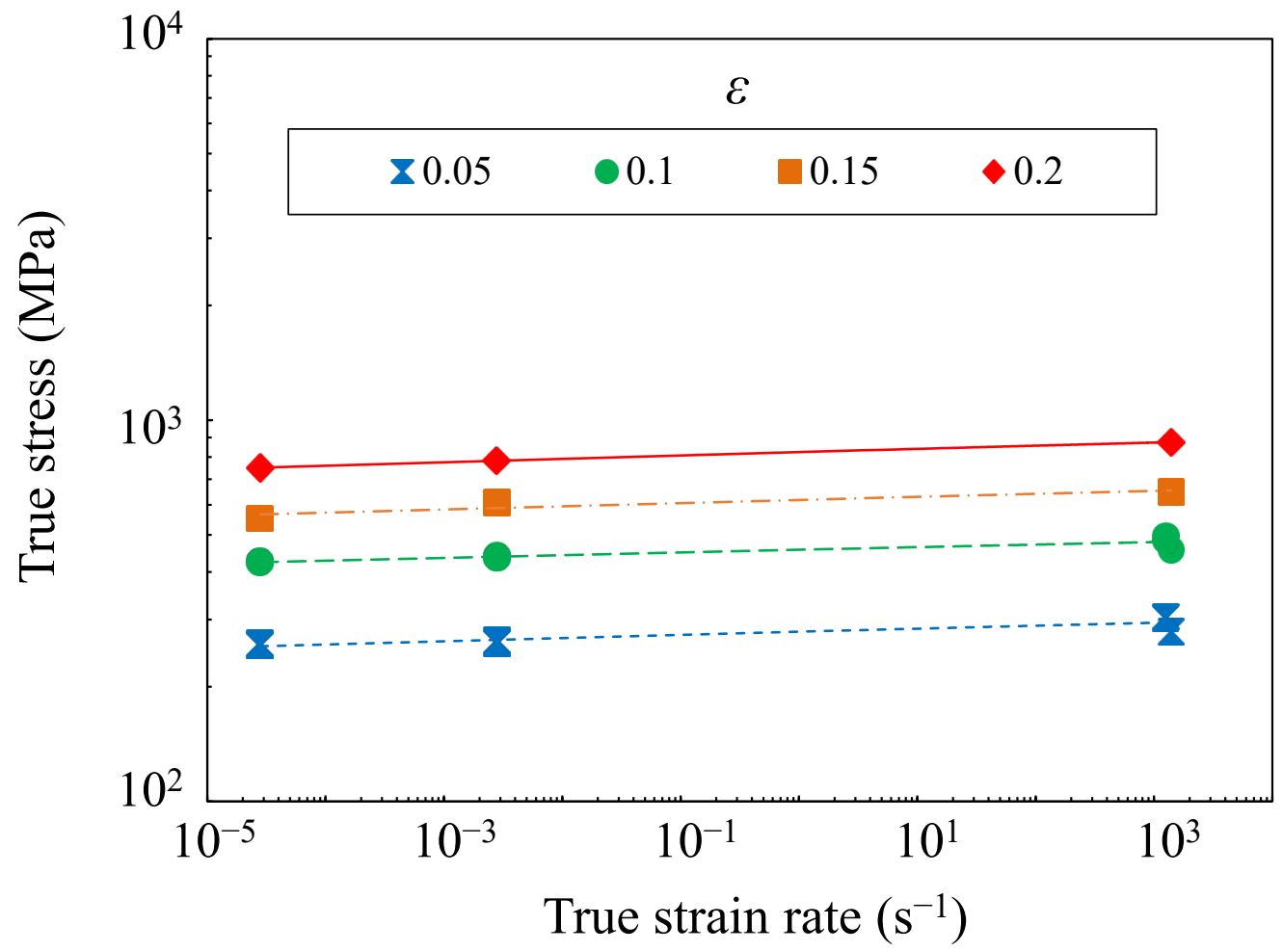

Figure 6. True stress-true strain rate relationships at strains of 0.05 to 0.2 for pure Ni: Results indicate $m \leq 0.009$ : an exceedingly small value.

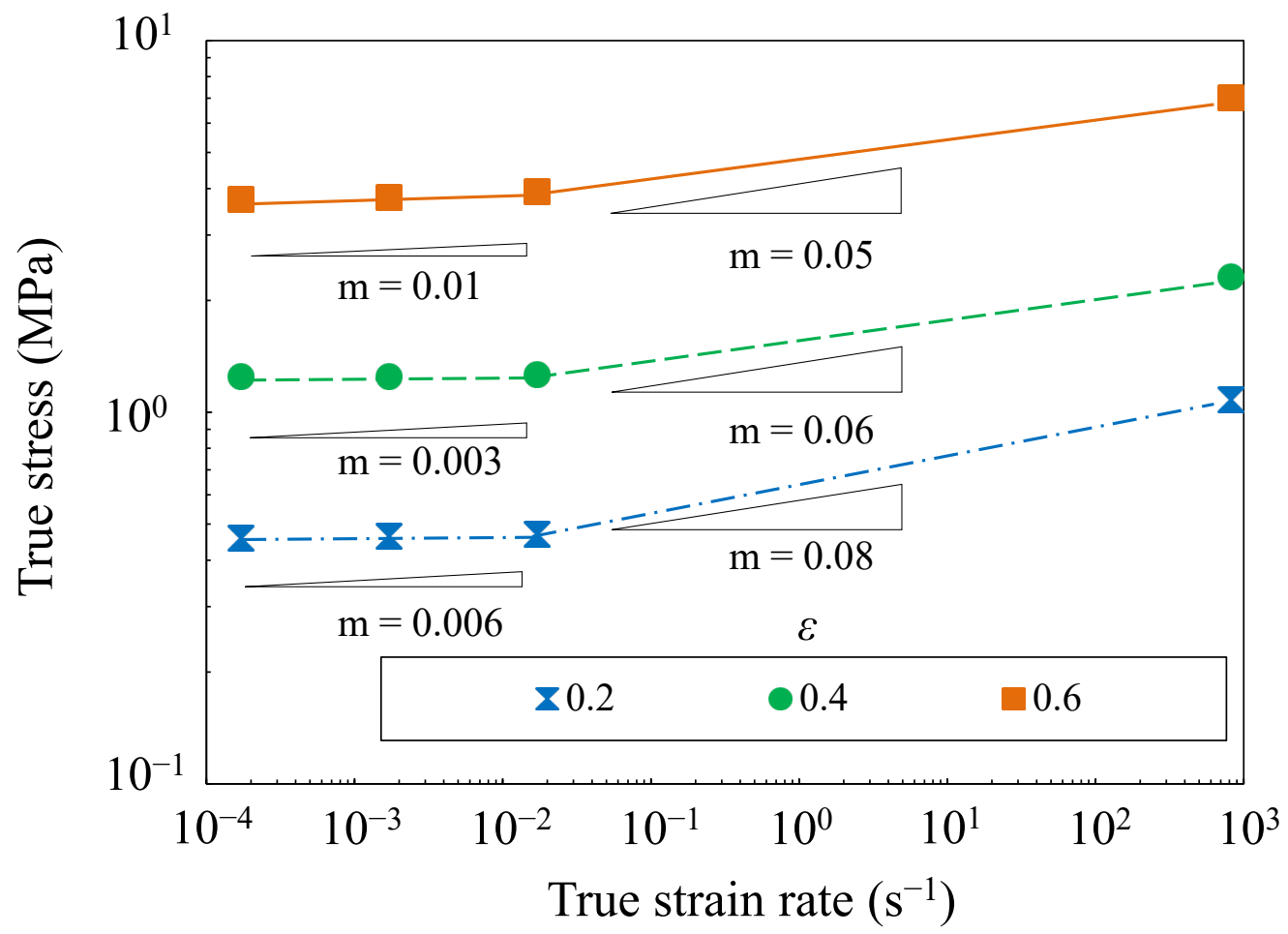

Figure 7. True stress-true strain rate relationships at strains of 0.2 to 0.6 for silicone rubber. 


\section{Results of Compression Tests of Cell Structure}

\subsection{Compression Velocity of $20.0 \mathrm{~m} / \mathrm{s}$ or Less}

\subsubsection{Ni Foam}

In this study, the stress was corrected to suppress the variation caused by the differences in specimen density [20]:

$$
\sigma_{n}=\sigma \times\left(\frac{\rho_{\text {ref }}}{\rho_{\text {cell }}}\right)^{x}
$$

where $\sigma_{n}$ is the flow stress after correction (normalized stress), $\rho_{\text {cell }}$ is the bulk density of individual specimens, $\rho_{\text {ref }}$ is the average bulk density of all specimens (in case of Ni foam, $\rho_{\text {ref }}=479 \mathrm{~kg} / \mathrm{m}^{3}$ ), and $x$ is the density sensitivity index. Density sensitivity index $x$ of the $\mathrm{Ni}$ foam in this study was 2.19 .

Figure 8 shows the typical normalized stress-strain relationship of $\mathrm{Ni}$ foam at strain rates between $8.3 \times 10^{-4}$ and $3.8 \times 10^{2} \mathrm{~s}^{-1}$, which correspond to compression velocities of $20.0 \mathrm{~m} / \mathrm{s}$ or less. Since the figure confirms no difference in the time history of the loads on both ends of all specimens at a compression velocity of $20.0 \mathrm{~m} / \mathrm{s}$ or less, only the values of the movable load cell are shown here. Regardless of the strain rate, we observed elastic, plateau, and densification regions corresponding to the three stages in the general deformation processes of a cell structure [2]. No change in the normalized stress with an increasing strain rate was confirmed. This tendency is identical as that of the strain rate dependence in the base metal $\mathrm{Ni}$. For the $\mathrm{Ni}$ foam, the pores are filled with air, and because it is an open cell, hardly any air compression occurs. Therefore, this structure clearly shows no strain rate dependence.

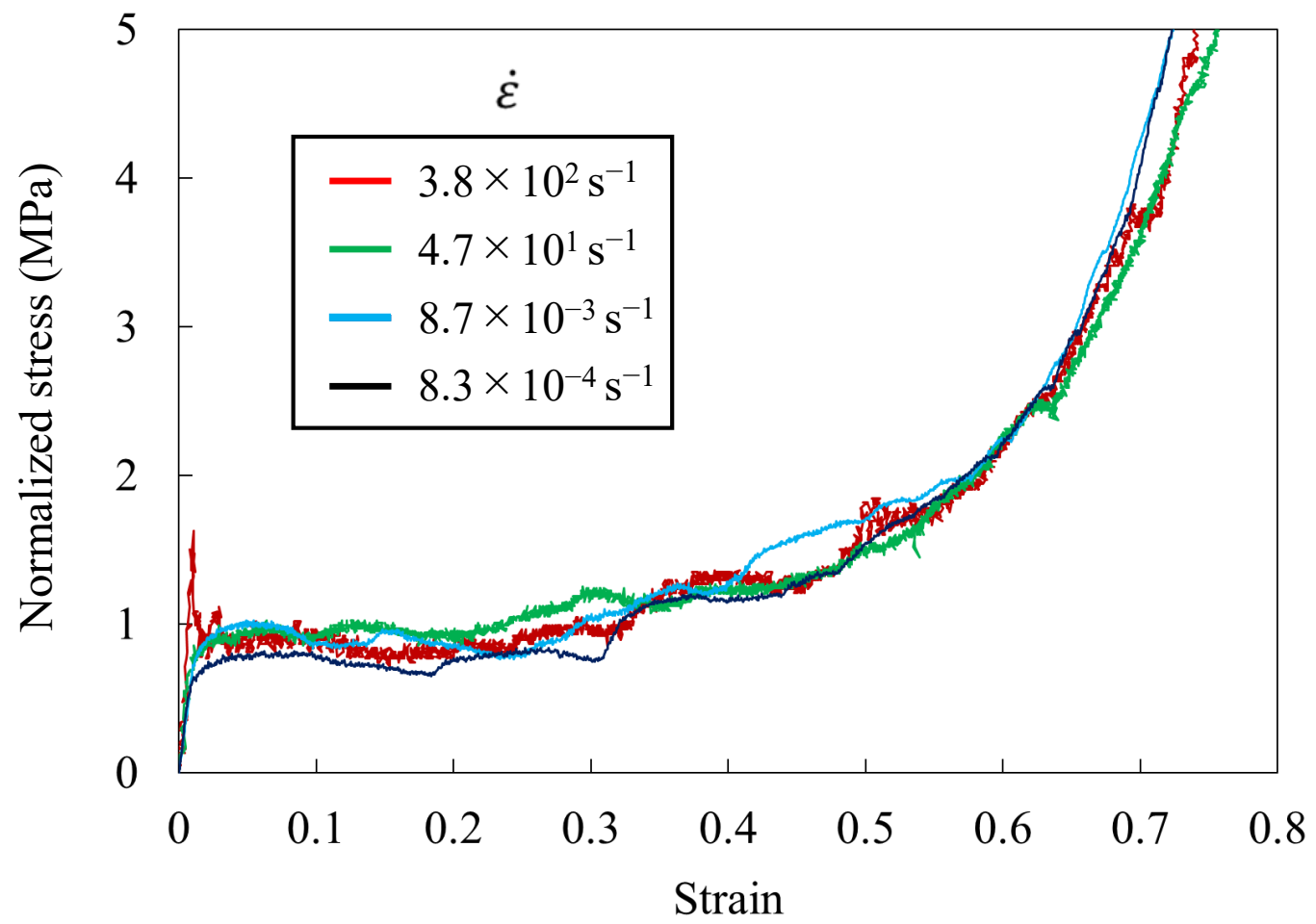

Figure 8. Typical normalized stress-strain relationship of Ni foam at a strain rate between $8.3 \times 10^{-4}$ and $3.8 \times 10^{2} \mathrm{~s}^{-1}$.

No nonuniform deformation due to high-speed deformation was observed at compression velocities of $20.0 \mathrm{~m} / \mathrm{s}$ or less, and deformation occurred throughout the entire specimen. In other words, local deformation, which occurred sequentially from the part with the lowest normalized stress inside the specimen, occurred simultaneously throughout. Because the load histories of the movable and stationary load cells were identical, 
the load at both ends of the specimen clearly reached force equilibrium at a compression velocity of $20.0 \mathrm{~m} / \mathrm{s}$ or less.

\subsubsection{Ni/Silicone Foam}

Figure 9 shows a typical normalized stress-strain relationship for $\mathrm{Ni}$ / silicone foam at strain rates between $8.3 \times 10^{-4}$ and $3.8 \times 10^{2} \mathrm{~s}^{-1}$. For comparison, the Ni results at a strain rate of $8.3 \times 10^{-4} \mathrm{~s}^{-1}$ are also shown. The load at both ends in all the $\mathrm{Ni} /$ silicone foam for this strain rate range was identical when the compression velocity was $20.0 \mathrm{~m} / \mathrm{s}$ or less; only the values of the movable load cell are shown here. A comparison of the quasi-static test results of the $\mathrm{Ni}$ foam and the $\mathrm{Ni}$ / silicone foam confirmed that the latter shows increased normalized stress in the plateau region because the silicone rubber inside the structure was also compressed. The normalized stresses again coincide in the densified region because the silicone rubber flows out with densification.

Next, the normalized stress was confirmed to increase remarkably with a higher strain rate in the $\mathrm{Ni}$ /silicone foam, clarifying that the $\mathrm{Ni}$ / silicone foam with silicone rubber void-filling material has a strain rate dependence of normalized stress. This includes the strain rate dependence of the normalized stress confirmed for the silicone rubber alone but also the normalized stress increase due to the silicone rubber's flow. In the densified region, the quasi-static test identified the same tendency as that observed in the $\mathrm{Ni}$ foam. To investigate the increase in the normalized stress with an increasing strain rate and the change in the densification start time in detail, we focused on the deformation behavior of the $\mathrm{Ni}$ / silicone foam.

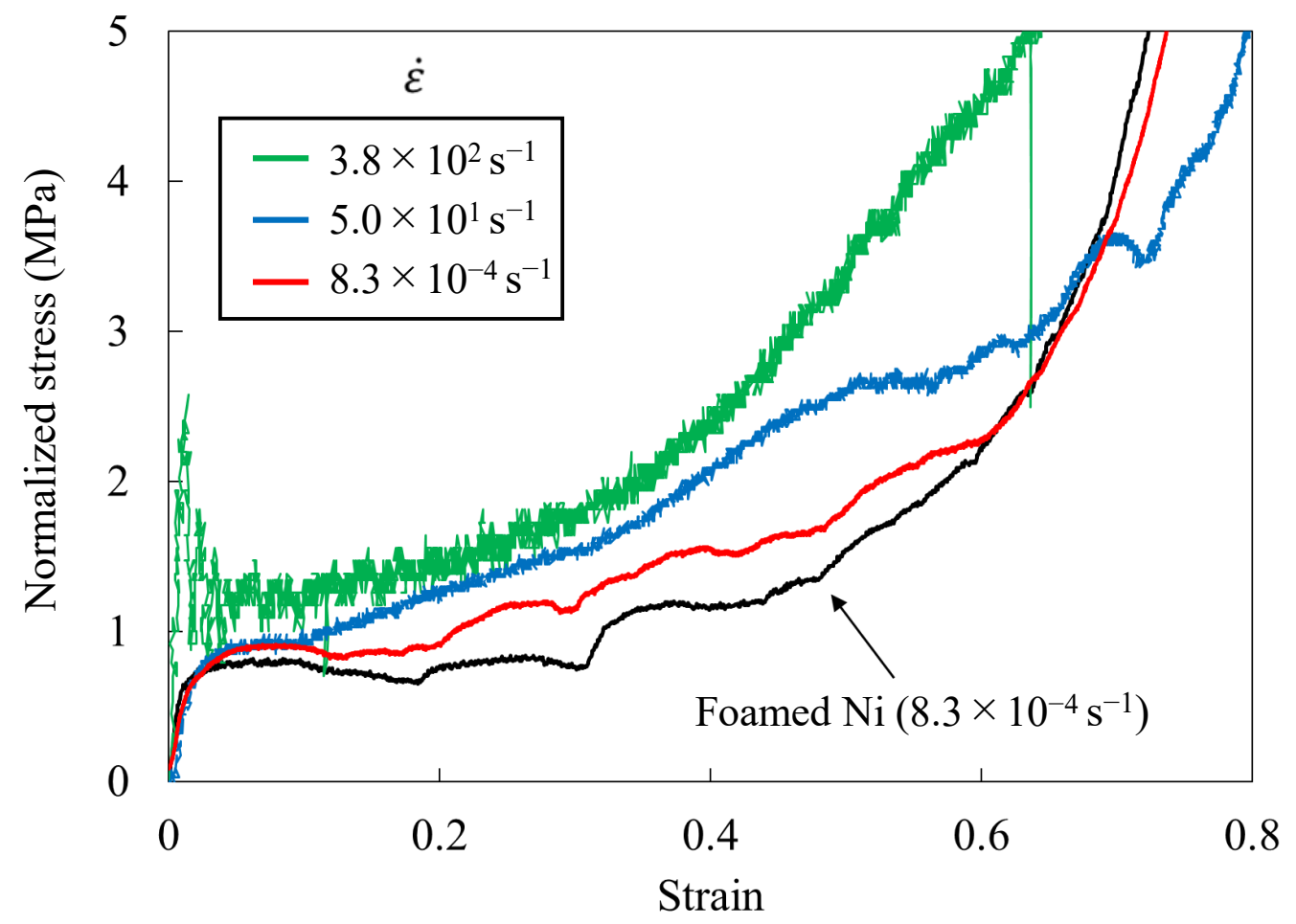

Figure 9. Typical normalized stress-strain relationship of $\mathrm{Ni}$ / silicone foam at strain rates between $8.3 \times 10^{-4}$ and $3.8 \times 10^{2} \mathrm{~s}^{-1}$.

Figure 10 shows the deformation behavior of the $\mathrm{Ni}$ foam and the $\mathrm{Ni}$ / silicone foam at a strain rate of $8.3 \times 10^{-4} \mathrm{~s}^{-1}$. In the quasi-static test of $\mathrm{Ni}$ foam, no nonuniform deformation was observed from the end of the specimen, although random deformation was observed from the weak part of the cell struts. At this time, no swelling was observed in the direction perpendicular to the compression direction, and the sample exhibited a compressive deformation behavior with a Poisson's ratio of almost zero. In the $\mathrm{Ni}$ / silicone foam quasi-static test, as the deformation progressed, the silicone rubber flowed out at a 
strain of 0.4 , and most flowed out at a strain of 0.6. The results of the quasi-static test for the $\mathrm{Ni}$ / silicone foam indicate that the resistance due to the compression of the silicone rubber might contribute to an increase in the normalized stress at the initial stage of deformation. However, because silicone rubber extrudes from inside the cell as it densifies, it stops contributing to the normalized stress increase in the densified region. Figure 11 shows the deformation of the $\mathrm{Ni}$ / silicone foam at a strain of 0.6 for strain rates of $5.0 \times 10^{1}$ and $3.8 \times 10^{2} \mathrm{~s}^{-1}$. Despite the equal strain, as the strain rate increases, the outflow of the silicone rubber filler decreases and more rubber remains inside. This may be because the compression velocity is higher than the outflow velocity of the silicone rubber, so the silicone rubber lacks sufficient time to flow out. The remaining silicone rubber may have contributed to the increase in the normalized stress under compressive deformation.

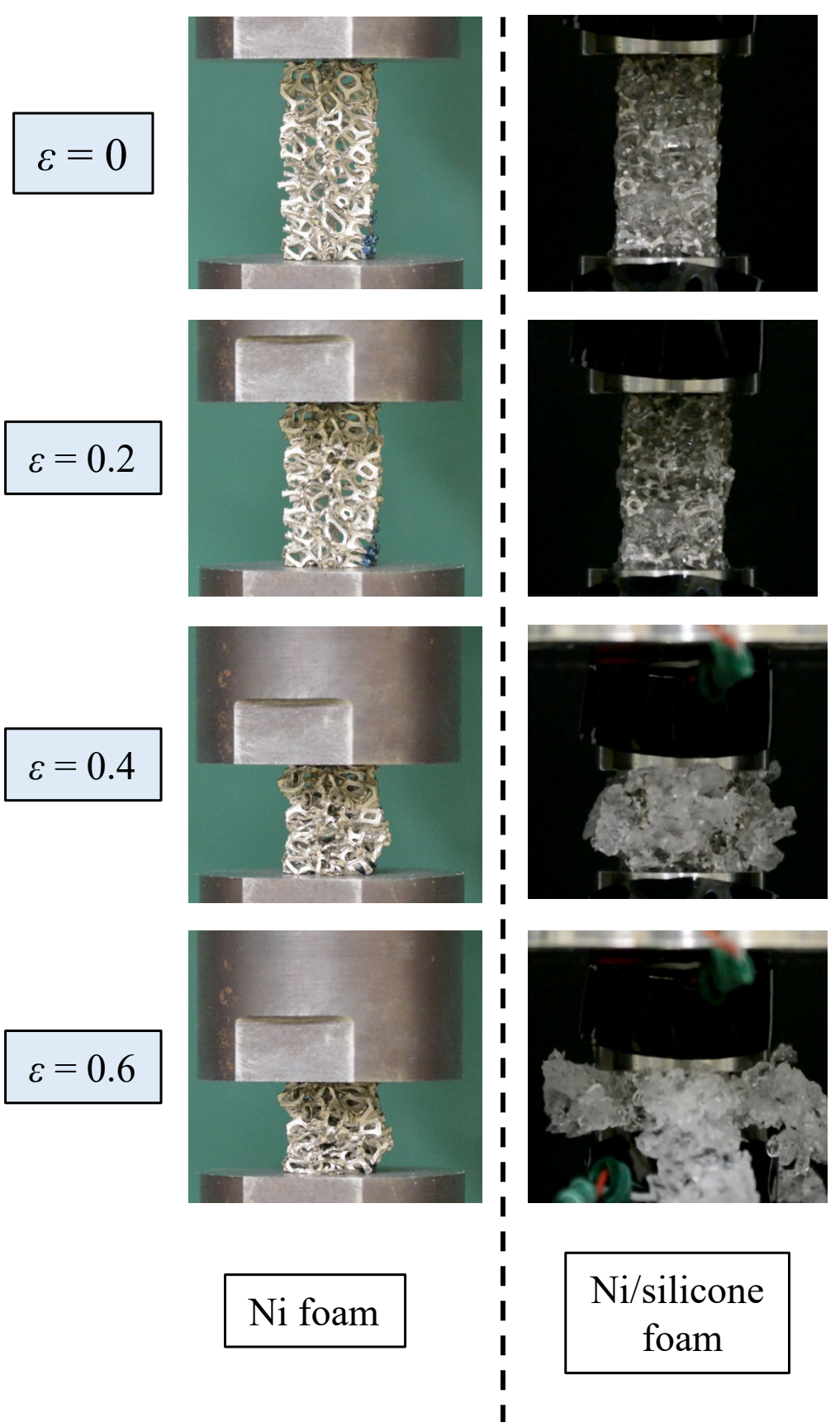

Figure 10. Deformation behavior of $\mathrm{Ni}$ foam and $\mathrm{Ni} /$ silicone foam at strain rate of $8.3 \times 10^{-4} \mathrm{~s}^{-1}$. 


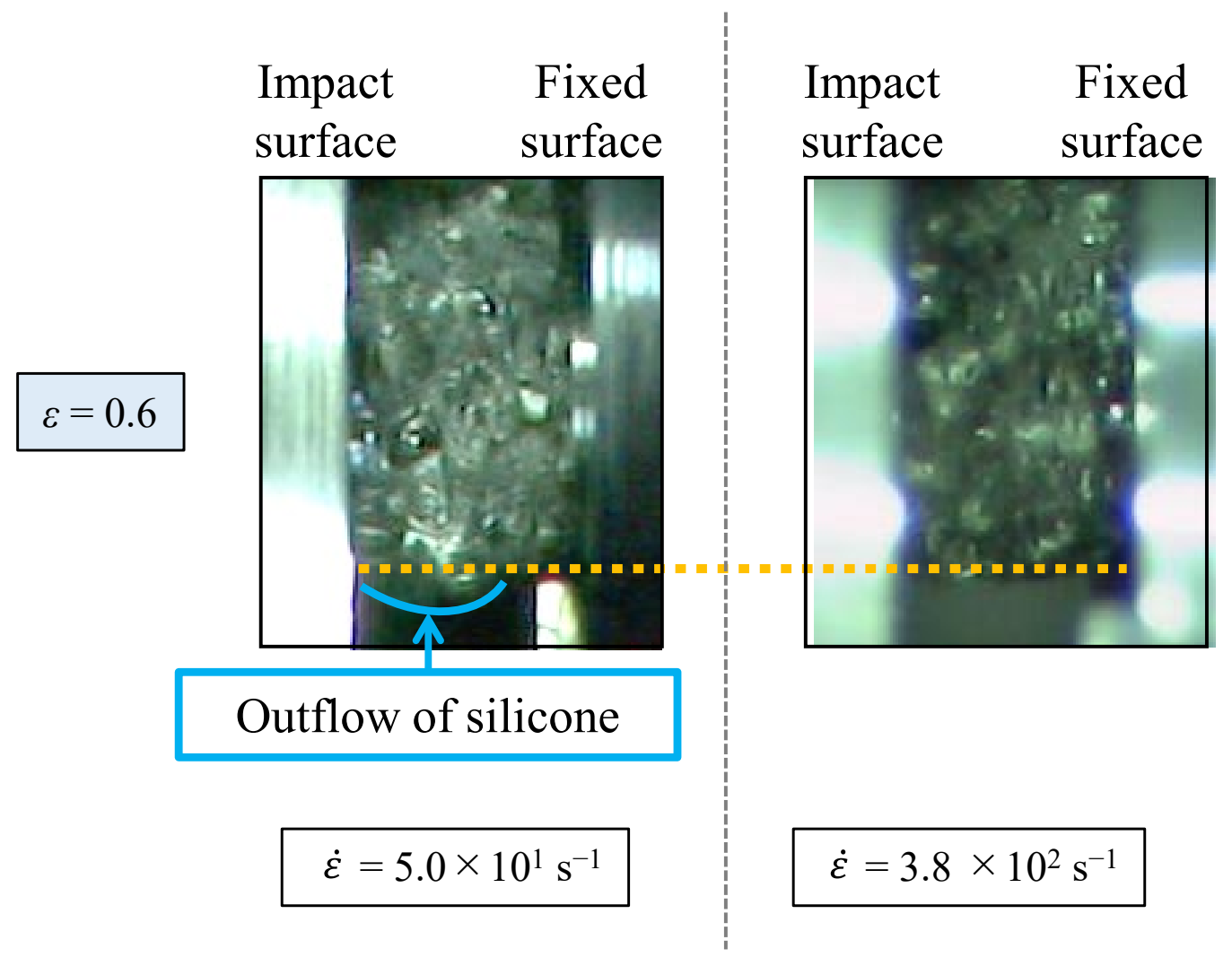

Figure 11. Deformation of Ni/silicone foam at strain of 0.6 for strain rates of $5.0 \times 10^{1}$ and $3.8 \times 10^{2} \mathrm{~s}^{-1}$.

Next, we focused on the specimen state after each compression test because the deformation can be tracked to only a limited extent from the moving images captured using the high-speed camera. Figure 12 shows each specimen after the compression test at strain rates of $8.3 \times 10^{-4}$ and $3.8 \times 10^{2} \mathrm{~s}^{-1}$. After the quasi-static test, the $\mathrm{Ni}$ foam showed almost no deformation perpendicular to the compression direction and exhibited folded deformation. The Ni/silicone foam showed almost the same deformation of the cell structure as the $\mathrm{Ni}$ foam, excluding silicone rubber outflow. By contrast, in the impact test, the $\mathrm{Ni}$ foam and the $\mathrm{Ni}$ /silicone foam showed significantly different deformation states. With Ni foam, since the specimen shape was almost the same as that in the quasi-static test, the deformation behavior remain unchanged. On the other hand, with the $\mathrm{Ni}$ / silicone foam, the cell struts formed by $\mathrm{Ni}$ was caught in the deformation of the silicone rubber, and it fractured and scattered in all directions. Perhaps the silicone rubber did not flow out and was subjected to compressive deformation, causing expansion perpendicular to the compression direction owing to a high Poisson's ratio. The outflow of silicon is pushing the structs to deform in a random direction, causing easier failure.

In the dynamic test, the start of densification after a strain of 0.7 was slower than that in the quasi-static compression test (Figure 9). Perhaps the silicone rubber flowed out at a strain of 0.7 . The out-flowing silicone rubber incorporated cell struts, decreasing the ratio of the $\mathrm{Ni}$ foam occupied by the $\mathrm{Ni}$ / silicone foam. By contrast, in the impact test, since the compression velocity of the silicone rubber was higher than its outflow rate, it did not flow out before densification; the relative density was increased due to the space occupied by this silicone, and the start of densification occurred at a low strain. This clearly indicates that the void-filling material significantly affects the deformation behavior of the cell structure. Generally, when the void-filling material is a low-viscosity fluid, such as air, it is hardly affected by the strain rate at a compression velocity of $20 \mathrm{~m} / \mathrm{s}$ or less, although the velocity largely influences highly viscous silicone rubber. 


\subsection{Compression Velocity of $20.0 \mathrm{~m} / \mathrm{s}$ or More}

Figures 13 and 14 show the normalized stress-strain relationship of the Ni foam and the $\mathrm{Ni}$ /silicone foam during impact tests conducted at the maximum compression velocity of the test apparatus: approximately $26.0 \mathrm{~m} / \mathrm{s}$ (strain rate: $1.3 \times 10^{3} \mathrm{~s}^{-1}$ ). When the compression velocity was $26.0 \mathrm{~m} / \mathrm{s}$, since the load histories obtained from the load cells at both ends of the specimen differed, the normalized stresses of the movable and stationary load cells are shown. The strain was calculated by dividing the displacement generated in the specimen by its original length. Similar to the dense material described above, the vibration of the movable load cell is a natural period. The normalized stress increase in the stationary load cell was delayed with respect to the normalized stress increase in the movable load cell due to the propagation of elastic waves.
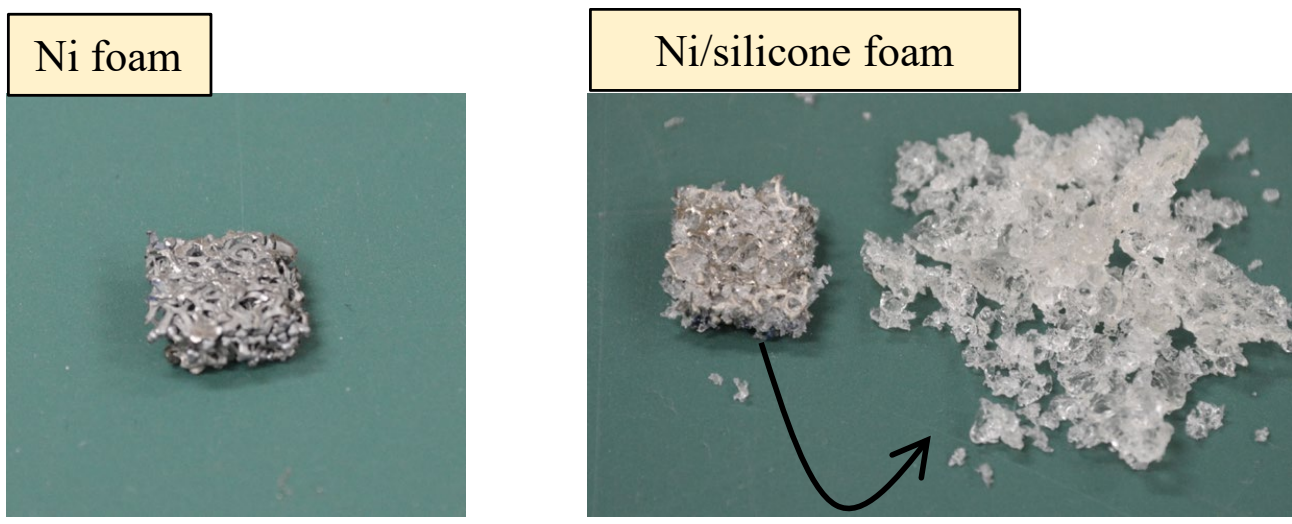

Flowed out silicone

(a) $8.3 \times 10^{-4} \mathrm{~s}^{-1}$
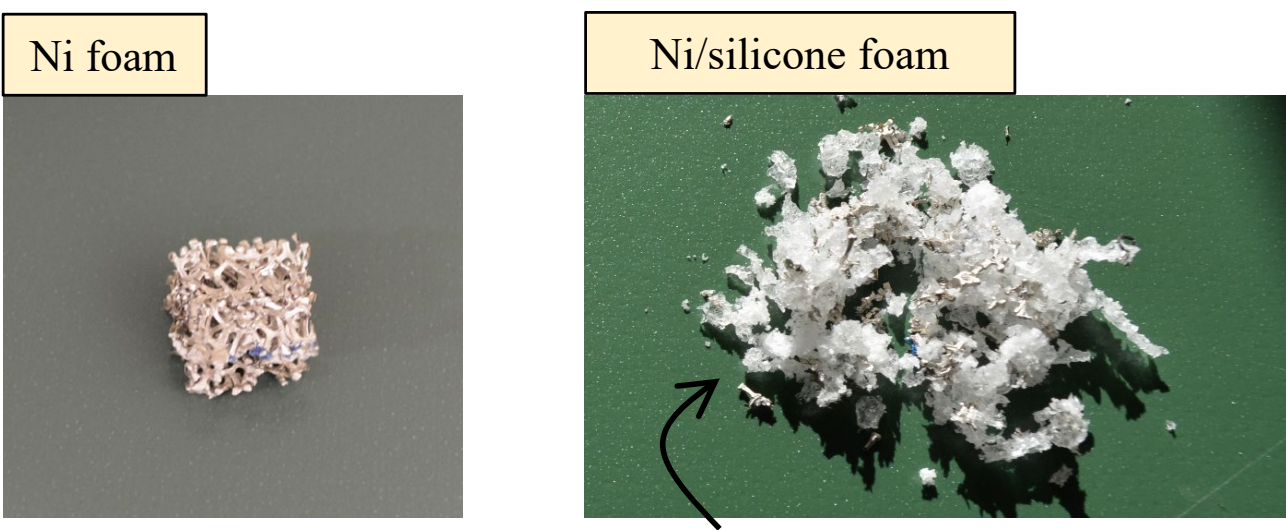

Mixed state of fractured nickel and silicone

(b) $3.8 \times 10^{2} \mathrm{~s}^{-1}$

Figure 12. Each specimen after compression test at strain rates of $8.3 \times 10^{-4}(\mathbf{a})$ and $3.8 \times 10^{2} \mathrm{~s}^{-1}(\mathbf{b})$. 


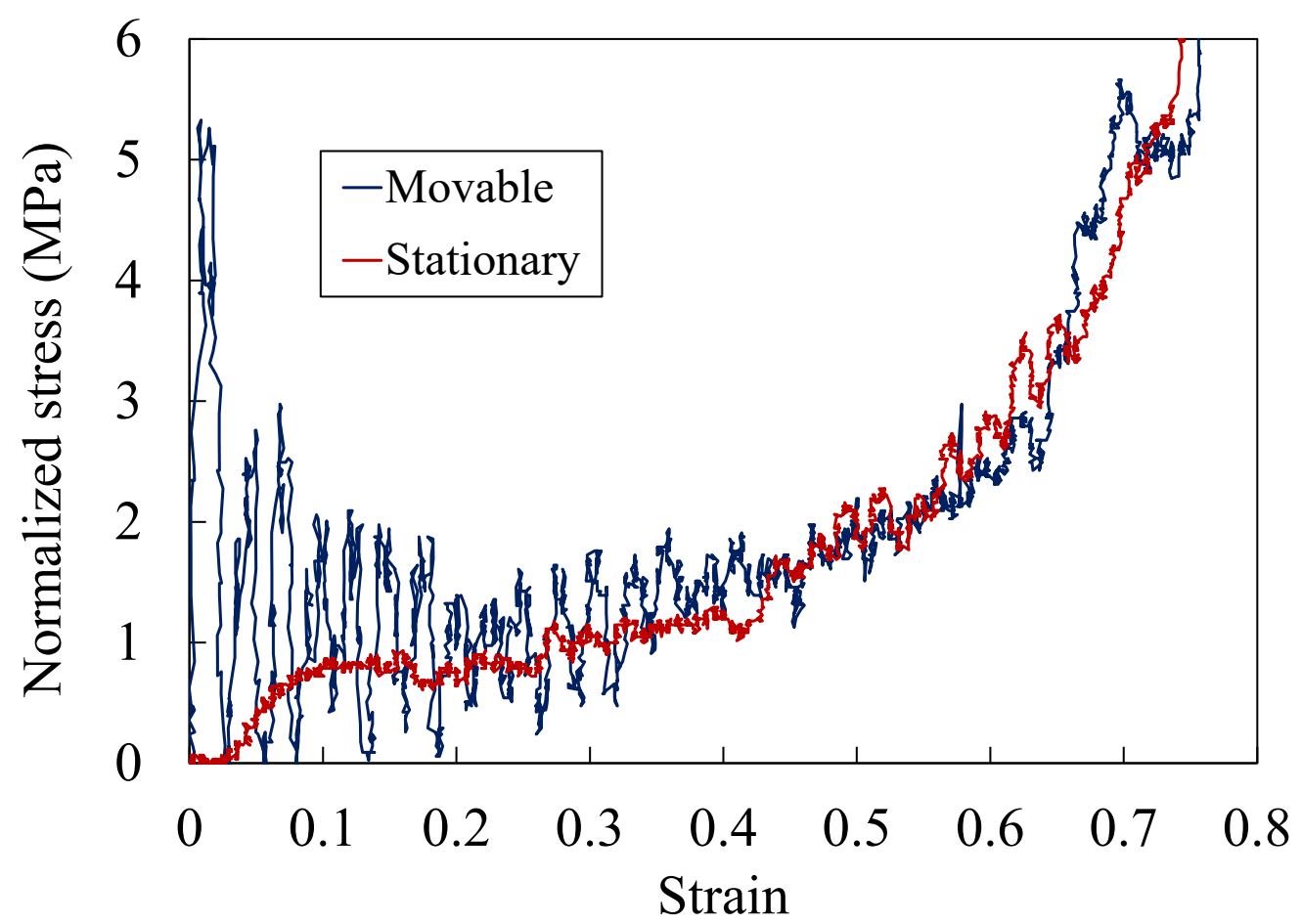

Figure 13. Typical normalized stress-strain relationship of Ni foam in an impact test conducted at compression rate of approximately $26.0 \mathrm{~m} / \mathrm{s}$.

In the plateau region, the load value of the movable load cell exceeded that obtained from the stationary load cell, and the normalized stresses at the two ends almost matched as the deformation proceeded for a $\mathrm{Ni}$ foam strain of up to 0.25 ; the Ni-silicone strain reached 0.4. These results indicate that the stress applied to the two ends of the specimens did not match at the initial stage of deformation at a compression velocity of approximately $26.0 \mathrm{~m} / \mathrm{s}$, and no force equilibrium was achieved for either specimen. The normalized stress increase of the movable load cell was larger than that of the stationary load cell for the $\mathrm{Ni}$ /silicone foam.

Figure 15 shows the deformation behavior of the $\mathrm{Ni}$ foam and the $\mathrm{Ni}$ / silicone foam at a compression velocity of approximately $26.0 \mathrm{~m} / \mathrm{s}$ (strain rate: $1.3 \times 10^{3} \mathrm{~s}^{-1}$ ). For the $\mathrm{Ni}$ foam, the nonuniform deformation could not be observed clearly from the impact end, where the compression velocity was $26.0 \mathrm{~m} / \mathrm{s}$ or less. In addition, for the $\mathrm{Ni} /$ silicone foam, no clear wavefront of nonuniform deformation was observed in the process. Observing the wavefront only by visualization is difficult. However, silicone rubber greatly expanded owing to the compressive deformation on the impact end at the beginning of deformation ( $\varepsilon=0.1$ and 0.2 in Figure 15), and this expansion was transmitted from the impact end to the fixed end; similar observations for Ni foam were unclear. At this time, the Ni/silicone foam showed uniform deformation at a strain of 0.4 or more. The load history of the movable and stationary load cells did not match in the $\mathrm{Ni}$ /silicone foam compression test at a compression velocity of $26.0 \mathrm{~m} / \mathrm{s}$, possibly due to this nonuniform deformation. However, no clear nonuniform deformation was observed in the Ni foam, despite the fact that the normalized stress at the two ends of the specimen was not in equilibrium. Perhaps the transition velocities at which nonuniform deformation occurs differ between the $\mathrm{Ni}$ foam and the $\mathrm{Ni} /$ silicone foam. 


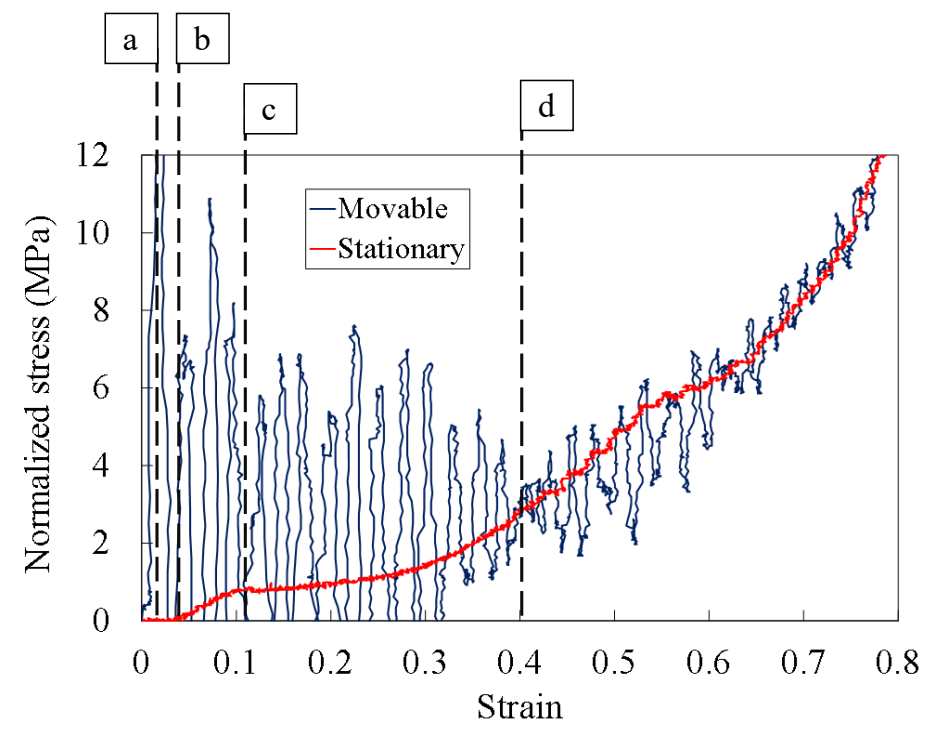

Figure 14. Typical normalized stress-strain relationship of $\mathrm{Ni}$ /silicone foam in an impact test conducted at a compression rate of approximately $25.6 \mathrm{~m} / \mathrm{s}$ : (a-d) correspond to the stress wave propagation behavior in Figure 19.

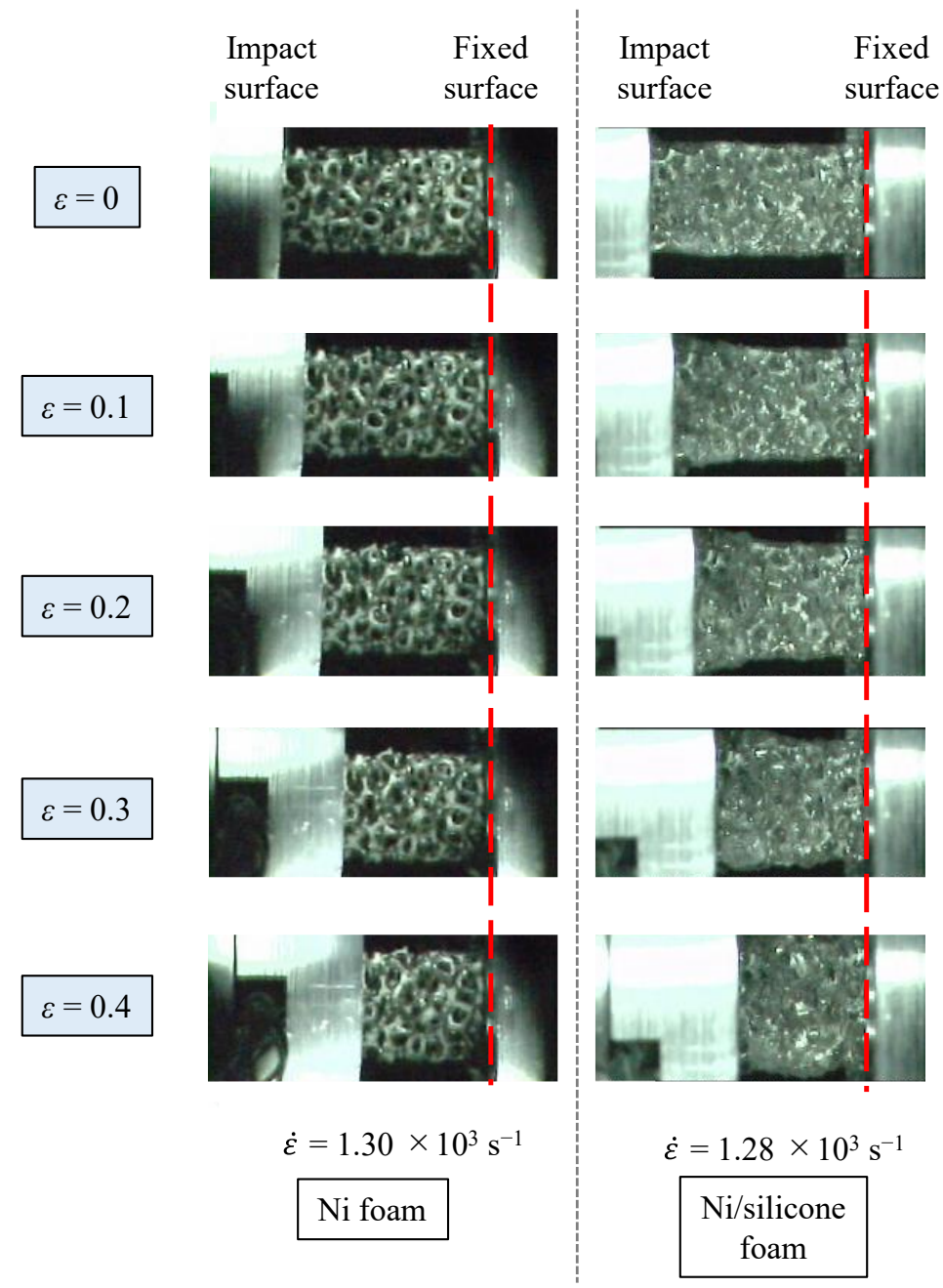

Figure 15. Deformation behavior of $\mathrm{Ni}$ foam and $\mathrm{Ni} /$ silicone foam at compression rate of approximately $26.0 \mathrm{~m} / \mathrm{s}$. 
As discussed above, we experimentally confirmed the nonuniform deformation and reproduced the transition velocity at which it occurred. The specimens with identical cell structure suggested various deformation behaviors due to different void-filling materials. The next section discusses the mechanism of nonuniform deformation based on these results.

\section{Discussion of Mechanism of Nonuniform Deformation}

The discontinuous state, which occurs in solids, was evaluated in previous studies using the Rankine-Hugoniot relation based on the mass conservation law, the momentum conservation law, and the energy conservation law. For example, Barns et al. showed that the following relations are satisfied before and after the discontinuity surface [22]:

$$
\begin{gathered}
\varepsilon_{H}=\frac{\left(S_{0}-S_{1}\right)}{S_{0}} \\
C_{s}=\frac{V_{i}}{\varepsilon_{H}} \\
\sigma_{d}=\sigma_{u d}+\rho_{u d} \frac{V_{i}^{2}}{\varepsilon_{H}} .
\end{gathered}
$$

As shown in Figure 16, the density, particle velocity, stress, and energy of the undeformed part are denoted as $\rho_{u d}, V_{u d}, \sigma_{u d}$, and $U_{u d}$, respectively, and those of the deformed part are denoted as $\rho_{d}, V_{d}, \sigma_{d}$, and $U_{d}$, respectively. In the above equations, $S_{0}$ is the length of the deformed part before the deformation, $S_{1}$ is its length after the deformation, $V_{i}$ is the compression velocity of the striking bar, $C_{S}$ is the speed of the wavefront of an inhomogeneous deformation (hereafter discontinuity surface) generated inside the specimen, and $\varepsilon_{H}$ is the strain before the discontinuity, also called the Hugoniot strain. The stress of the deformed part (the impact end of the deformed part of the specimen) can be obtained by calculating $\varepsilon_{H}$ by empirically finding $C_{s}$ and $V_{i}$ from Equations (3) and (4) and substituting it into Equation (5). An almost linear tendency is obtained between $C_{s}$ and $V_{i}$ in the cell structure:

$$
C_{s}=A+B V_{i}
$$

Here $A$ and $B$ are constants. $A$ corresponds to the bulk sound speed of a solid, as observed in many solid materials [22].

However, it is essential to measure the compression velocity and the speed of the discontinuity surface from the captured image of the deformation behavior to conduct an evaluation with the Rankine-Hugoniot relation with the above method. The above method is suitable if the collision velocity is sufficiently high and a nonuniform deformation is clearly generated. As shown in Figure 15, observing a clear discontinuity is difficult, especially near the transition velocity. Even when using a digital image correlation, accurate observation was complicated by the coarse cell structure and the transparent silicone rubber. Therefore, confirming whether the Rankine-Hugoniot relation is satisfied near the transition velocity is hard with conventional methods. In this study, the deformation mechanism is discussed based on the test and observation results on the same time axis obtained using the load-measuring apparatus with opposite load cells. 


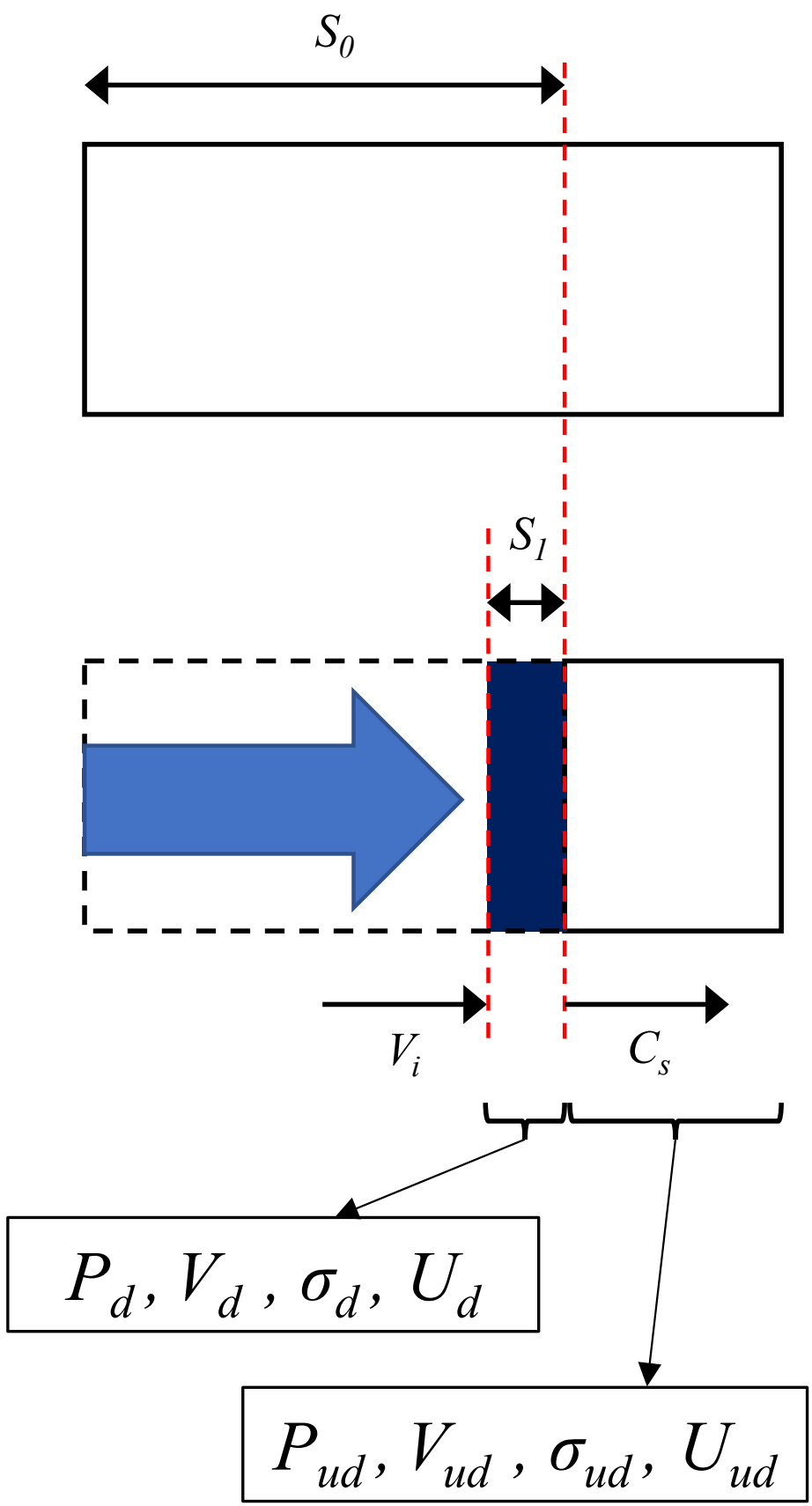

Figure 16. Physical quantity inside material during nonuniform deformation.

Figure 17 shows the simple stress-strain relationship of a typical cell structure. The elastic modulus of cell structure $E_{e}$ is the slope of the elastic response, and strain-hardening exponent $E_{p}$ is the slope of the plateau region. In other words, when the bulk density of the specimen is $\rho_{\text {cell }}$, plastic stress wave speed $C_{p}$ is expressed as:

$$
C_{p}=\sqrt{\frac{E_{p}}{\rho_{\text {cell }}}} .
$$

We calculated the plastic stress wave speed from the plateau region in the stress-strain relationship, and the results are reported in Figures 13 and 14 . For Ni foam, $E_{p}=250 \mathrm{kPa}$ in the initial stage of the plateau region, and $C_{p}=23.0 \mathrm{~m} / \mathrm{s}$ for specimen density $\rho_{\text {cell }}$ of $471.7 \mathrm{~kg} / \mathrm{m}^{3}$. For $\mathrm{Ni} / \mathrm{silicone}$ foam, $E_{c}=325 \mathrm{kPa}$ in the initial stage of the plateau region, and $C_{p}=15.7 \mathrm{~m} / \mathrm{s}$ for specimen density $\rho_{\text {cell }}$ of $1314.4 \mathrm{~kg} / \mathrm{m}^{3}$. In other words, the 
compression velocity of the impact test was higher than the plastic stress wave speed in the initial stage of the plateau region in both specimens. As shown in Figures 8, 9, 13 and 14, strain-hardening exponent $\mathrm{n}$ is not constant, and the stress-strain curve has a convex shape down from the plateau region with increasing densification. Here, we examined cases where the compression velocity is sufficiently high and slightly higher than the plastic stress wave speed.

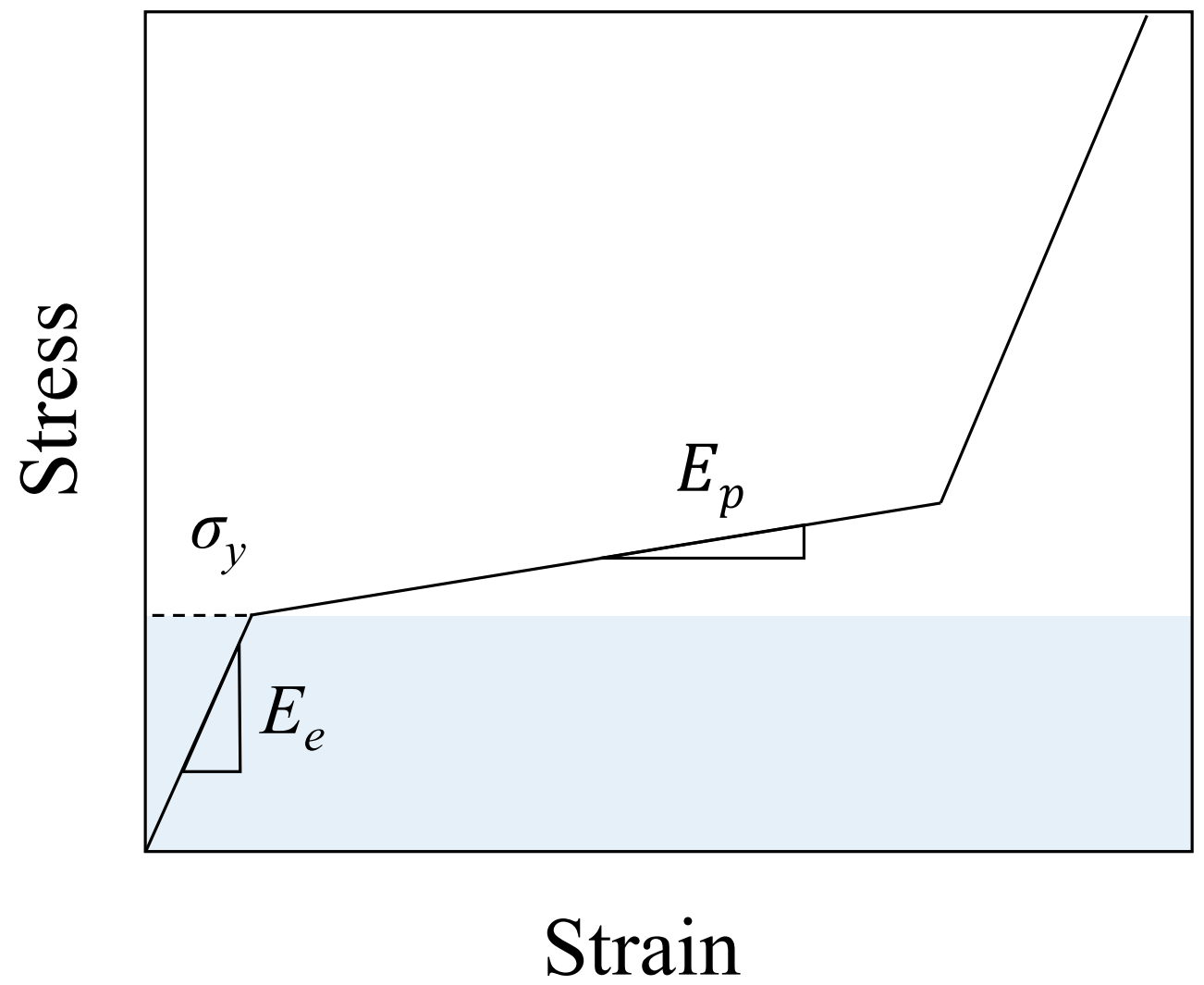

Figure 17. Simple stress-strain relationship of a typical cell structure.

When the compression velocity is sufficiently higher than the plastic stress wave speed, the impact surface catches up with the wavefront of the plastic stress wave over time, and a clear discontinuity surface is generated (Figure 18). Therefore, when the compression velocity is sufficiently higher than the plastic stress wave speed that causes deformation, a discontinuity surface is formed due to the accumulation of plastic stress waves as deformation progresses, and nonuniform deformation occurs from the impact end. At this time, the speed of the discontinuity surface from the accumulation of plastic stress waves corresponds to $C_{S}$ in a shock wave in a solid. This condition was experimentally confirmed at a discontinuity surface speed in the order of tens to hundreds of meters per second [16]. Because the elastic stress wave speed is much higher than the plastic stress wave speed, an elastic stress wave was found in the front of the discontinuity surface, although the ratio of the elastic deformation is very small compared to the deformation of the cell structure. The effect is considered very small.

Next, we consider the case where the compression velocity is slightly higher than the plastic stress wave speed, as shown in Figure 19. Figure 19a-d corresponds to the history of the experimental results shown in Figure 14. The impact surface approaches the wavefront of the plastic stress wave over time and forms a discontinuity surface owing to the accumulation of the plastic stress wave (Figure 19a,b). In Figure 19b, because only the elastic stress wave reaches the fixed end, the elastic region can be confirmed from the stress-strain relationship. At this time, because the compression velocity is almost the same as the plastic stress wave speed, the discontinuity surface due to the accumulation 
of plastic stress waves does not catch up with the wavefront of the plastic stress wave, and only the plastic stress wave arrives at the fixed end (Figure 19c). Therefore, a plastic deformation region (plateau region) was observed at the fixed end, even with the stressstrain relation shown in Figure 14, despite the fact that the stresses at the two ends did not achieve force equilibrium. Finally, the stresses at the two ends of the specimen were considered to have achieved force equilibrium when the discontinuity surface due to the accumulation of plastic stress waves reached the fixed end, as shown in Figure 19d. Strictly speaking, the discontinuity surface due to the accumulation of plastic stress waves is not a clear discontinuity surface because plastic deformations occur even in front of it. Further, random deformation is speculated to occur in the part where the front surface deforms, in the same way as in the deformation mode of $20 \mathrm{~m} / \mathrm{s}$ or less. Therefore, a clear observation is difficult using high-speed camera images.

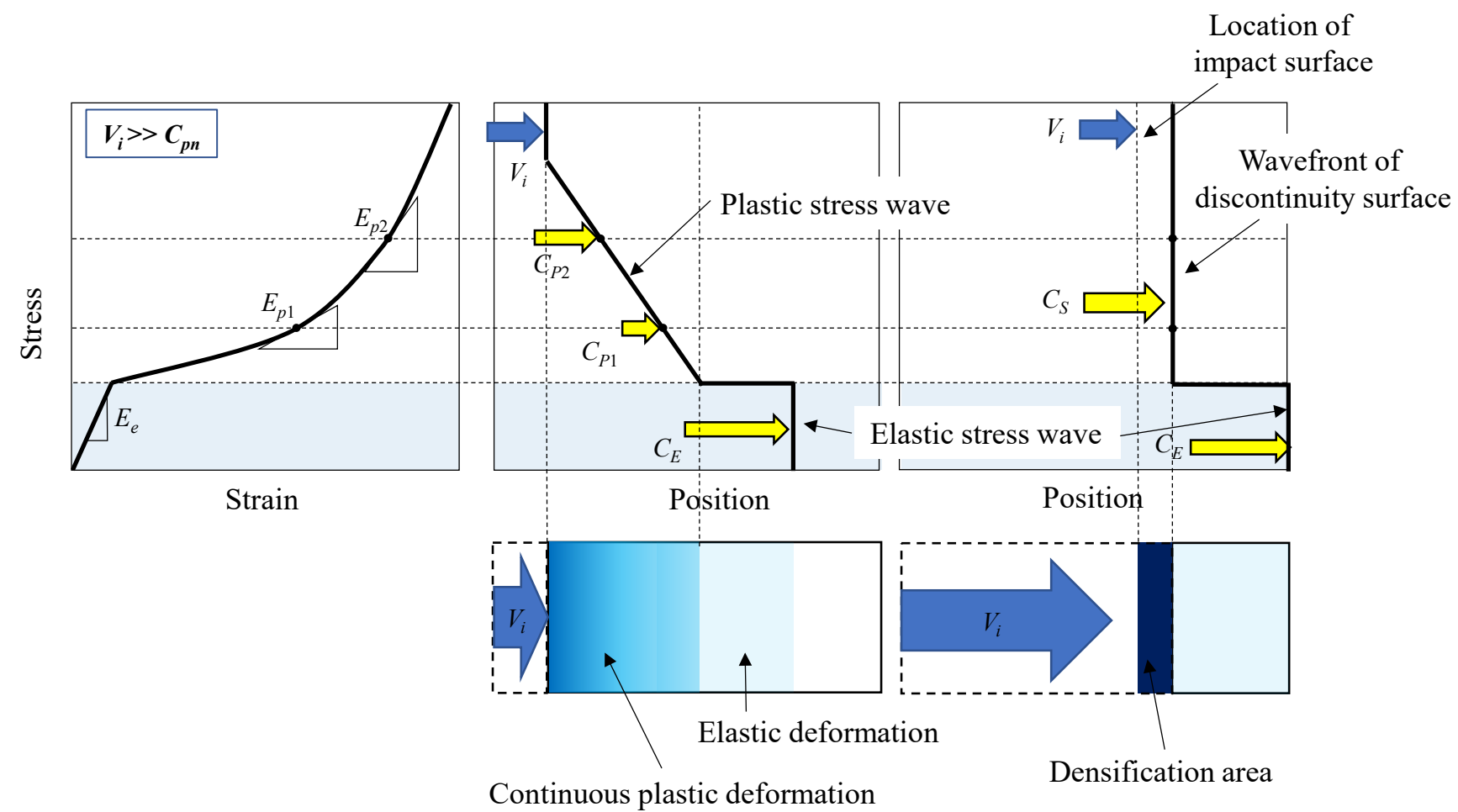

Figure 18. Stress wave propagation behavior when compression velocity is sufficiently higher than plastic stress wave speed.

The nonuniform deformation of the cell structure probably occurred owing to the accumulation of plastic stress waves. In contrast to the speed of the discontinuity surface from the accumulation of plastic stress waves, their speed depends on the shape of the plateau region and the density of the specimen; plastic stress wave speed is not constant and changes with time. Near the transition velocity, plastic deformation may occur even in front of the discontinuity surface from the accumulation of plastic stress waves, treating the deformation behavior as a distinct discontinuity surface. 

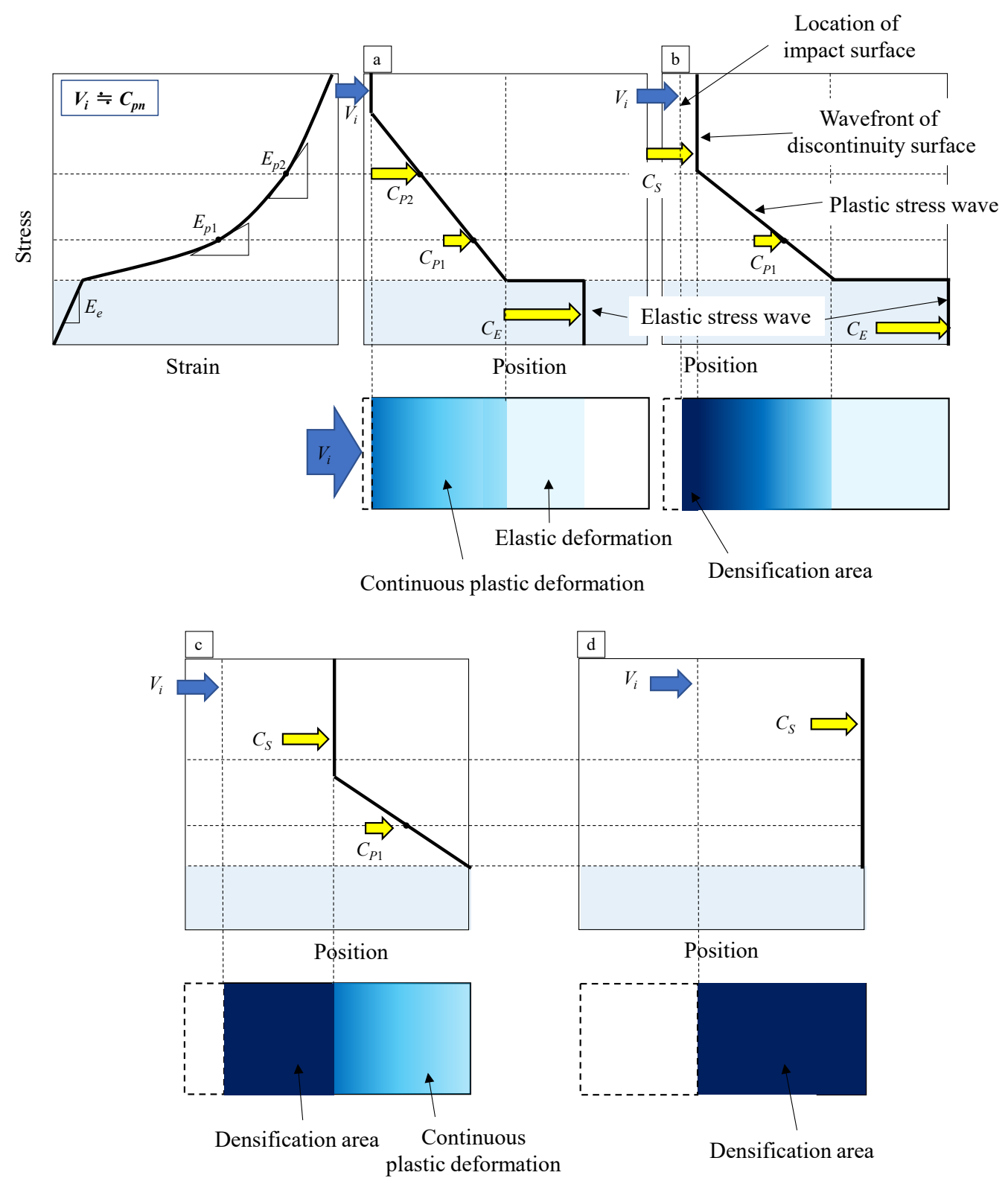

Figure 19. Stress wave propagation behavior where compression velocity is slightly higher than plastic stress wave speed: (a-d) correspond to the history of experimental results in Figure 14.

\section{Conclusions}

We used a new test apparatus that could evaluate load state at the impact and fixed ends in a one-time test and investigated stress wave propagation and clarified the nonuniform deformation mechanism of the cell structure of $\mathrm{Ni}$ foam and $\mathrm{Ni}$ /silicone foam. They obtained the following results:

1. At a compression velocity of $20.0 \mathrm{~m} / \mathrm{s}$ or less (strain rate from $8.3 \times 10^{-4}$ to $3.8 \times 10^{2} \mathrm{~s}^{-1}$ ), no nonuniform deformation was observed in either the $\mathrm{Ni}$ foam or the $\mathrm{Ni}$ / silicone foam, and the loads on the impact and fixed ends achieved force equilibrium.

2. The flow stress of the Ni foam did not show any change with an increasing strain rate; by contrast, the flow stress of the $\mathrm{Ni}$ / silicone foam showed remarkable strain rate dependence. Perhaps this result was caused by the outflow resistance when silicone flows out from the inside and the pressure rises owing to the residual silicone.

3. At a compression velocity of approximately $26.0 \mathrm{~m} / \mathrm{s}$ (strain rate: $1.3 \times 10^{3} \mathrm{~s}^{-1}$ ), the loads at both ends of the $\mathrm{Ni}$ /silicone foam differed, and we observed nonuniform deformation from the impact end. The plastic stress wave propagation speed in the 
$\mathrm{Ni}$ /silicone foam, derived from the slope of the plateau region, was $15.7 \mathrm{~m} / \mathrm{s}$, suggesting that nonuniform deformation occurs when the compression velocity becomes higher than the plastic stress wave propagation speed.

4. Nonuniform deformation of the cell structure was probably caused by the accumulation of plastic stress waves. However, near the transition velocity, plastic deformation can occur even in front of the discontinuity surface owing to the accumulation of plastic stress waves. Therefore, deformation behavior cannot be considered a distinct discontinuity surface.

Author Contributions: Conceptualization, K.T. and H.Y.; methodology, K.T. and H.Y.; validation, K.T. and H.Y.; investigation, K.T.; resources, H.Y.; data curation, K.T.; writing-original draft preparation, K.T.; writing-review and editing, H.Y.; visualization, K.T. All authors have read and agreed to the published version of the manuscript.

Funding: This work was supported by JSPS KAKENHI Grant Number 20K14615.

Acknowledgments: The authors thank Nagahisa Ogasawara and Chihiro Kakuno for their discussion and comments. The authors also thank Sekisui Chemical Co., Ltd. for their support in making the specimen.

Conflicts of Interest: The authors declare no conflict of interest.

\section{References}

1. Avalle, M.; Belingardi, G.; Montanini, R. Characterization of Polymeric Structural Foams under Compressive Impact Loading by Means of Energy-Absorption Diagram. Int. J. Impact Eng. 2001, 25, 455-472. [CrossRef]

2. Gibson, L.J.; Ashby, M.F. Cellular Solids: Structure and Properties, 2nd ed.; Cambridge University Press: Cambridge, UK, 1988; ISBN 9781139878326.

3. Saha, M.C.; Mahfuz, H.; Chakravarty, U.K.; Uddin, M.; Kabir, M.E.; Jeelani, S. Effect of Density, Microstructure, and Strain Rate on Compression Behavior of Polymeric Foams. Mater. Sci. Eng. A 2005, 406, 328-336. [CrossRef]

4. Bouix, R.; Viot, P.; Lataillade, J.L. Polypropylene Foam Behaviour under Dynamic Loadings: Strain Rate, Density and Microstructure Effects. Int. J. Impact Eng. 2009, 36, 329-342. [CrossRef]

5. Liao, S.; Zheng, Z.; Yu, J. On the Local Nature of the Strain Field Calculation Method for Measuring Heterogeneous Deformation of Cellular Materials. Int. J. Solids Struct. 2014, 51, 478-490. [CrossRef]

6. Gasparetto, V.E.L.; ElSayed, M.S.A. Multiscale Modelling and Mechanical Anisotropy of Periodic Cellular Solids with RigidJointed Truss-Like Microscopic Architecture. Appl. Mech. 2021, 2, 331-355. [CrossRef]

7. Adachi, H.; Hasegawa, T. Effects of Cell Destruction on Compression Moduli of Closed-Celled Polyethylene Foams. Nihon Reoroji Gakkaishi 2003, 31, 105-108. [CrossRef]

8. Chakravarty, U.; Mahfuz, H.; Saha, M.; Jeelani, S. Strain Rate Effects on Sandwich Core Materials: An Experimental and Analytical Investigation. Acta Mater. 2003, 51, 1469-1479. [CrossRef]

9. Ouellet, S.; Cronin, D.; Worswick, M. Compressive Response of Polymeric Foams under Quasi-Static, Medium and High Strain Rate Conditions. Polym. Test. 2006, 25, 731-743. [CrossRef]

10. Song, B.; Chen, W.; Lu, W.Y. Compressive Mechanical Response of a Low-Density Epoxy Foam at Various Strain Rates. J. Mater. Sci. 2007, 42, 7502-7507. [CrossRef]

11. Fowles, R.; Williams, R.F. Plane Stress Wave Propagation in Solids. J. Appl. Phys. 1970, 41, 360-363. [CrossRef]

12. Meyers, M.A. Dynamic Behavior of Materials; Wiley: Hoboken, NJ, USA, 1994; ISBN 9780471582625.

13. Elnasri, I.; Pattofatto, S.; Zhao, H.; Tsitsiris, H.; Hild, F.; Girard, Y. Shock Enhancement of Cellular Structures under Impact Loading: Part I Experiments. J. Mech. Phys. Solids 2007, 55, 2652-2671. [CrossRef]

14. Pattofatto, S.; Elnasri, I.; Zhao, H.; Tsitsiris, H.; Hild, F.; Girard, Y. Shock Enhancement of Cellular Structures under Impact Loading: Part II Analysis. J. Mech. Phys. Solids 2007, 55, 2672-2686. [CrossRef]

15. Wang, P.; Xu, S.; Li, Z.; Yang, J.; Zhang, C.; Zheng, H.; Hu, S. Experimental Investigation on the Strain-Rate Effect and Inertia Effect of Closed-Cell Aluminum Foam Subjected to Dynamic Loading. Mater. Sci. Eng. A 2015, 620, 253-261. [CrossRef]

16. Gaitanaros, S.; Kyriakides, S. Dynamic Crushing of Aluminum Foams: Part II-Analysis. Int. J. Solids Struct. 2014, 51, 1646-1661. [CrossRef]

17. Hopkinson, B.X. A Method of Measuring the Pressure Produced in the Detonation of High, Explosives or by the Impact of Bullets. Philos. Trans. R. Soc. Lond. Ser. Contain. Pap. Math. Phys. Character 1914, 213, 437-456. [CrossRef]

18. Kolsky, H. An Investigation of the Mechanical Properties of Materials at Very High Rates of Loading. Proc. Phys. Soc. Sect. B 1949, 62, 676-700. [CrossRef]

19. Tateyama, K.; Kakuno, C.; Ogasawara, N.; Yamada, H. Development of Universal Rate Range Load-Cell. J. Jpn. Soc. Exp. Mech. 2017, 17, 131-138. [CrossRef] 
20. Yamada, H.; Kakuno, C.; Tateyama, K.; Ogasawara, N. Development of Dynamic and Impact Load-Measuring Apparatus with Opposite Load-Cells. J. Jpn. Soc. Exp. Mech. 2017, 17, 117-123. [CrossRef]

21. Tateyama, K.; Yamada, H.; Ogasawara, N. Effect of Strain Rate on Compressive Properties of Foamed Polyethylene Film. Polym. Test. 2016, 52, 54-62. [CrossRef]

22. Barnes, A.T.; Ravi-Chandar, K.; Kyriakides, S.; Gaitanaros, S. Dynamic Crushing of Aluminum Foams: Part I-Experiments. Int. J. Solids Struct. 2014, 51, 1631-1645. [CrossRef] 